\title{
Extreme IR absorption in group IV-SiGeSn core-shell nanowires
}

Anis Attiaoui, Stephan Wirth, André-Pierre Blanchard-Dionne, Michel Meunier, J. M. Hartmann, Dan Buca, and Oussama Moutanabbir

Citation: Journal of Applied Physics 123, 223102 (2018); doi: 10.1063/1.5021393

View online: https://doi.org/10.1063/1.5021393

View Table of Contents: http://aip.scitation.org/toc/jap/123/22

Published by the American Institute of Physics

\section{Articles you may be interested in}

Atomically uniform Sn-rich GeSn semiconductors with 3.0-3.5 $\mu \mathrm{m}$ room-temperature optical emission Applied Physics Letters 112, 251903 (2018); 10.1063/1.5038644

Direct bandgap type-I GeSn/GeSn quantum well on a GeSn- and Ge- buffered Si substrate AIP Advances 8, 025104 (2018); 10.1063/1.5020035

Analysis of dependent scattering mechanism in hard-sphere Yukawa random media Journal of Applied Physics 123, 223101 (2018); 10.1063/1.5030504

Optical properties of lonsdaleite silicon nanowires: A promising material for optoelectronic applications Journal of Applied Physics 123, 224301 (2018); 10.1063/1.5025856

Propagation of $\mathrm{THz}$ pulses in rectangular subwavelength dielectric waveguides

Journal of Applied Physics 123, 223103 (2018); 10.1063/1.5030515

Topological Dirac semimetal phase in $\mathrm{Ge}_{\mathrm{x}} \mathrm{Sn}_{\mathrm{y}}$ alloys

Applied Physics Letters 112, 251601 (2018); 10.1063/1.5037121

\section{AIP |roumal af}

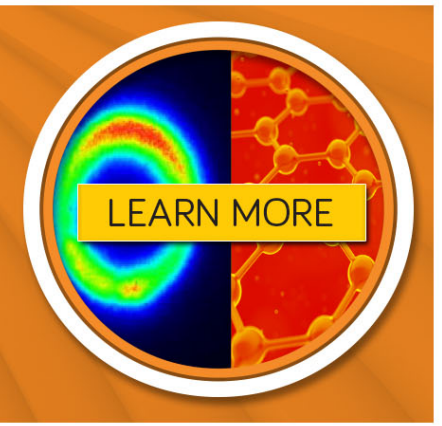




\title{
Extreme IR absorption in group IV-SiGeSn core-shell nanowires
}

\author{
Anis Attiaoui, ${ }^{1}$ Stephan Wirth, ${ }^{2}$ André-Pierre Blanchard-Dionne, ${ }^{1}$ Michel Meunier, ${ }^{1}$ \\ J. M. Hartmann, ${ }^{3}$ Dan Buca, ${ }^{2}$ and Oussama Moutanabbir ${ }^{1, a)}$ \\ ${ }^{1}$ Department of Engineering Physics, École Polytechnique de Montréal, Montréal, C.P. 6079, \\ Succ. Centre-Ville, Montréal, Québec H3C 3A7, Canada \\ ${ }^{2}$ Peter Grünberg Institute 9 and JARA-FIT, Forschungszentrum Juelich, 52425 Juelich, Germany \\ ${ }^{3}$ CEA, LETI, Minatec Campus, 17 rue des Martyrs, 38054 Grenoble, France
}

(Received 4 January 2018; accepted 13 May 2018; published online 11 June 2018)

\begin{abstract}
Sn-containing $\mathrm{Si}$ and $\mathrm{Ge}\left(\mathrm{Ge}_{1-\mathrm{y}-\mathrm{x}} \mathrm{Si}_{\mathrm{x}} \mathrm{Sn}_{\mathrm{y}}\right)$ alloys are an emerging family of semiconductors with the potential to impact group IV material-based devices. These semiconductors provide the ability to independently engineer both the lattice parameter and bandgap, which holds the premise to develop enhanced or novel photonic and electronic devices. With this perspective, we present detailed investigations of the influence of $\mathrm{Ge}_{1-\mathrm{y}-\mathrm{x}} \mathrm{Si}_{\mathrm{x}} \mathrm{Sn}_{\mathrm{y}}$ layers on the optical properties of $\mathrm{Si}$ and Ge based heterostructures and nanowires. We found that by adding a thin $\mathrm{Ge}_{1-\mathrm{y}-\mathrm{x}} \mathrm{Si}_{\mathrm{x}} \mathrm{Sn}_{\mathrm{y}}$ capping layer on $\mathrm{Si}$ or Ge greatly enhances light absorption especially in the near infrared range, leading to an increase in short-circuit current density. For the $\mathrm{Ge}_{1-\mathrm{y}-\mathrm{x}} \mathrm{Si}_{\mathrm{x}} \mathrm{Sn}_{\mathrm{y}}$ structure at thicknesses below $30 \mathrm{~nm}$, a 14fold increase in the short-circuit current is observed with respect to bare Si. This enhancement decreases by reducing the capping layer thickness. Conversely, decreasing the shell thickness was found to improve the short-circuit current in $\mathrm{Si} / \mathrm{Ge}_{1-\mathrm{y}-\mathrm{x}} \mathrm{Si}_{\mathrm{x}} \mathrm{Sn}_{\mathrm{y}}$ and $\mathrm{Ge} / \mathrm{Ge}_{1-\mathrm{y}-\mathrm{x}} \mathrm{Si}_{\mathrm{x}} \mathrm{Sn}_{\mathrm{y}}$ core/shell nanowires. The optical absorption becomes very important by increasing the Sn content. Moreover, by exploiting an optical antenna effect, these nanowires show extreme light absorption, reaching an enhancement factor, with respect to $\mathrm{Si}$ or Ge nanowires, on the order of $10^{4}$ in $\mathrm{Si} / \mathrm{Ge}_{0.84} \mathrm{Si}_{0.04} \mathrm{Sn}_{0.12}$ and $12 \mathrm{in} \mathrm{Ge} / \mathrm{Ge}_{0.84} \mathrm{Si}_{0.04} \mathrm{Sn}_{0.12}$. Furthermore, we analyzed the optical response after the addition of a dielectric layer of $\mathrm{Si}_{3} \mathrm{~N}_{4}$ to the $\mathrm{Si} / \mathrm{Ge}_{1-\mathrm{y}-\mathrm{x}} \mathrm{Si}_{\mathrm{x}} \mathrm{Sn}_{\mathrm{y}}$ core-shell nanowire and found approximatively a $50 \%$ increase in the short-circuit current density for a dielectric layer of thickness equal to $45 \mathrm{~nm}$ and both a core radius and a shell thickness greater than $40 \mathrm{~nm}$. The core-shell optical antenna benefits from a multiplication of enhancements contributed by leaky mode resonances in the semiconductor part and antireflection effects in the dielectric part. Published by AIP Publishing.

https://doi.org/10.1063/1.5021393
\end{abstract}

\section{INTRODUCTION}

Engineering light absorption and scattering in group IV semiconductors has been a powerful paradigm to implement innovative and high performance devices for solar cells, ${ }^{1}$ photodiodes, photodetectors, and plasmonics, ${ }^{2,3}$ to name a few. Of particular interest is developing cost-effective and high efficiency photovoltaic cells which rely crucially on the availability of affordable materials that can efficiently absorb light and convert it into charge carriers. Within this broad context, silicon $(\mathrm{Si})$ has been the material of choice due to its cost-effectiveness and its wide use in semiconductor technologies. However, despite its attractive electronic and material characteristics, Si has rather poor optical properties relative to its mainstream semiconductor counterparts due to its indirect bandgap and limited light absorption especially in the near-infrared region (NIR) and beyond, thus limiting the efficiency of Si-based solar cells. Consequently, electricity generated by Si solar cells, which currently make up over $90 \%$ of the photovoltaic market, is still 2-3 times more expensive than that from conventional fossil fuels which hinders their wide-scale adoption. ${ }^{4}$ In order to enhance the performance

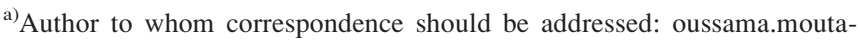
nabbir@polymtl.ca
}

of Si-based solar cells, a variety of strategies for light trapping through surface texturing and coating have been recently reported. ${ }^{5,6}$ Among these strategies, nanoscale structures such as nanowires (NWs) are emerging as versatile building blocks to enhance $\mathrm{Si}$ optical properties, thereby enabling a broad range of optoelectronic devices, ${ }^{7-9}$ such as photovoltaic cells, ${ }^{10-13}$ photodetectors, ${ }^{14-16}$ metamaterials, ${ }^{17-19}$ and thermal emitters. ${ }^{20}$ In this work, we demonstrate that Sn-containing group IV $\left(\mathrm{Ge}_{1-\mathrm{x}-\mathrm{y}} \mathrm{Si}_{\mathrm{x}} \mathrm{Sn}_{\mathrm{y}}\right)$ core-shell nanowire (CSNW) structures are effective in enhancing NIR light absorption in Si-based structures. We also demonstrate that this additional Sn-containing shell layer enhances the optical properties of germanium nanowires (GeNWs) as well.

$\mathrm{Ge}_{1-\mathrm{x}-\mathrm{y}} \mathrm{Si}_{\mathrm{x}} \mathrm{Sn}_{\mathrm{y}}$ is an emerging semiconductor system providing two degrees of freedom for band structure engineering, namely, alloying and strain. This ability to independently manipulate the strain and lattice parameter is central to engineer novel, group IV, low-dimensional systems and heterostructures in a similar fashion to the mature III-V materials. Moreover, unlike the indirect bandgap of $\mathrm{Si}$ and $\mathrm{Ge}$, a direct bandgap semiconductor can be achieved using Sn-containing alloys, thus providing a promising path towards Si-compatible efficient devices for emission and detection of light. ${ }^{21,22}$ The nature of the bandgap and its energy depend on the composition of the alloys. ${ }^{23-26}$ In the 
following, we begin by studying the structural properties and crystalline quality of the $\mathrm{Ge}_{1-\mathrm{x}-\mathrm{y}} \mathrm{Si}_{\mathrm{x}} \mathrm{Sn}_{\mathrm{y}}$ layers at variable compositions. Next, the optical properties of these layers are investigated using spectroscopic ellipsometry. The obtained optical properties of the analyzed layers were introduced to a Mie-scattering formalism using cylindrical CSNWs to evaluate the effects of the NW dimensions on the scattering and absorption properties. We start by demonstrating the optical antenna effects in individual SiNWs and GeNWs, which form the basic building blocks of our proposed CSNW structures. We then continue with the optimization of their absorption efficiencies by engineering the best possible match between the absorption spectrum of the wires and the visible range $(0.4-0.75 \mu \mathrm{m})$, as well as the Near-Infrared (NIR) range $(0.75-1.4 \mu \mathrm{m})$. In addition, as a figure of merit of the absorption efficiency, we analyze the photocurrent of different group IV $\mathrm{Ge}_{1-\mathrm{x}-\mathrm{y}} \mathrm{Si}_{\mathrm{x}} \mathrm{Sn}_{\mathrm{y}}$ based films and nanowire structures: $\quad \mathrm{Si} / \mathrm{Ge}_{1-\mathrm{x}-\mathrm{y}} \mathrm{Si}_{\mathrm{x}} \mathrm{Sn}_{\mathrm{y}} \quad \mathrm{CSNWs}, \quad \mathrm{Ge} / \mathrm{Ge}_{1-\mathrm{x}-\mathrm{y}} \mathrm{Si}_{\mathrm{x}} \mathrm{Sn}_{\mathrm{y}}$ CSNWs, and CSNWs wrapped in non-absorbing, anti-reflection coating (ARC) layers. Using these structures, we achieved extremely large absorption and scattering enhancements as compared to SiNWs, GeNWs, and thin films.

\section{EXPERIMENTAL AND THEORETICAL DETAILS}

\section{A. Growth of $\mathrm{Ge}_{1-\mathrm{x}-\mathrm{y}} \mathrm{Si}_{\mathrm{x}} \mathrm{Sn}_{\mathrm{y}}$ samples}

These layers were grown using a metal, cold-walled, reduced pressure chemical vapor deposition AIXTRON TRICENTR $^{\circledR}$ (RP-CVD) for $200 / 300 \mathrm{~mm}$ wafers. ${ }^{22}$ The growth of $\mathrm{Ge}_{1-\mathrm{x}-\mathrm{y}} \mathrm{Si}_{\mathrm{x}} \mathrm{Sn}_{\mathrm{y}}$ layers was performed on $\mathrm{Si}$ (100) wafers using low-defect density Ge virtual substrates. ${ }^{27-29}$ The epitaxial layers were grown using $\mathrm{Si}_{2} \mathrm{H}_{6}, \mathrm{Ge}_{2} \mathrm{H}_{6}(10 \%$ diluted in $\mathrm{H}_{2}$ ), and $\mathrm{SnCl}_{4}$ precursors using $\mathrm{N}_{2}$ as a carrier gas, which warrant reasonable growth rates at temperatures in the $350-475^{\circ} \mathrm{C}$ range. The $\mathrm{Ge}_{1-\mathrm{x}-\mathrm{y}} \mathrm{Si}_{\mathrm{x}} \mathrm{Sn}_{\mathrm{y}}$ layers were grown with $\mathrm{Si}$ and $\mathrm{Sn}$ concentrations in the range of $4 \%-20 \%$ and $2 \%-12 \%$, respectively. Prior to Raman investigations, the composition and structural properties of $\mathrm{Ge}_{1-\mathrm{x}-\mathrm{y}}$ $\mathrm{Si}_{\mathrm{x}} \mathrm{Sn}_{\mathrm{y}} / \mathrm{Ge} / \mathrm{Si}$ layers were characterized using Rutherford backscattering spectrometry (RBS), X-ray reciprocal space mapping (RSM), and transmission electron microscopy (TEM).

\section{B. Optical characterisation}

The optical measurements were performed with a commercial ellipsometer (variable-angle spectroscopic ellipsometer by J. A. Woollam) ${ }^{30}$ with a rotating polarizer and an auto-retarder that allows us to measure an ellipsometric angle between $0^{\circ}$ and $360^{\circ}$ and thus to obtain an accurate measurement in the spectral regions of small absorption. The angle of incidence was varied using an automatic goniometer stage between $45^{\circ}$ and $75^{\circ}$ for the $\mathrm{Ge}_{1-y} \mathrm{Sn}_{\mathrm{y}}$ samples and between $70^{\circ}$ and $80^{\circ}$ for the $\mathrm{Ge}_{1-\mathrm{x}-\mathrm{y}} \mathrm{Si}_{\mathrm{x}} \mathrm{Sn}_{\mathrm{y}}$ samples. A fundamental issue for accurate data extraction is the surface state, namely, the surface roughness and oxidation. For the grown $\mathrm{Ge}_{1-\mathrm{x}} \mathrm{Sn}_{\mathrm{x}}$ and $\mathrm{Ge}_{1-\mathrm{x}-\mathrm{y}} \mathrm{Si}_{\mathrm{x}} \mathrm{Sn}_{\mathrm{y}}$ layers, surfaces roughness and oxidation are the main issues. In order to circumvent the oxidation of the $\mathrm{Ge}_{1-\mathrm{y}} \mathrm{Sn}_{\mathrm{y}}$ and $\mathrm{Ge}_{1-\mathrm{x}-\mathrm{y}} \mathrm{Si}_{\mathrm{x}} \mathrm{Sn}_{\mathrm{y}}$ layers, a chemical treatment consisting of an $\mathrm{HCl}(38 \%)$ : deionized (DI)- $\mathrm{H}_{2} \mathrm{O}$ wet etch has been performed in order to reduce the thickness of the naturally formed oxide layers, rinsed in propanol (5 $\mathrm{min})$, and then blown dry with a nitrogen gun.

\section{Structural and optical properties}

Detailed investigations of structural and optical properties of $\mathrm{Ge}_{1-\mathrm{x}-\mathrm{y}} \mathrm{Si}_{\mathrm{x}} \mathrm{Sn}_{\mathrm{y}}$ semiconductors are still in their infancy despite their scientific and technological importance. Herein, in order to extract the optical properties needed for a more accurate theoretical treatment of the light-NW interaction, we employed spectroscopic ellipsometry to characterize $\mathrm{Ge}_{1-\mathrm{x}-\mathrm{y}} \mathrm{Si}_{\mathrm{x}} \mathrm{Sn}_{\mathrm{y}}$ thin layers. Figures 1(a) and 1(b) exhibit high-resolution Scanning Transmission Electron Microscopy (STEM) images near the $\mathrm{Ge}_{1-\mathrm{x}-\mathrm{y}} \mathrm{Si}_{\mathrm{x}} \mathrm{Sn}_{\mathrm{y}} / \mathrm{Ge}$ interface for two different $\mathrm{Sn}$ and $\mathrm{Si}$ compositions $[(\mathrm{x}, \mathrm{y})=(12 \%, 4 \%)$ and $(4 \%, 12 \%)$, respectively]. These figures clearly indicate the high crystalline quality of the epitaxially grown $\mathrm{Ge}_{1-\mathrm{x}-\mathrm{y}} \mathrm{Si}_{\mathrm{x}} \mathrm{Sn}_{\mathrm{y}}$ layers. X-ray reciprocal space mapping (not shown) confirmed that the grown layers are strained with an out-of-plane tetragonal distortion, typical to pseudomorphic growth, in agreement with the electron diffraction patterns [Figs. 1(a) and 1(b), inset]. The latter also demonstrate the absence of Sn precipitates despite the Sn content exceeding by several factors its equilibrium solubility $(<1.1$ at. $\%)$ which is a characteristic of metastable growth techniques. ${ }^{31}$

Next, the optical properties of the grown films were investigated at room temperature using a Variable-Angle Spectroscopic Ellipsometer (VASE). Using the visible-UV instrument, the dielectric function of our samples was determined from 1 to $5 \mathrm{eV}$ with $0.01 \mathrm{eV}$ steps based on measurements at four different angles of incidence. The ellipsometric data processing is elaborated in the supplementary material (Sec. S1). After extracting the optical constants, we incorporated the complex refractive index into a Lorenz-Mie formalism in order to quantify the absorption, scattering, and extinction efficiencies of CSNW, as it will be shown in Sec. IID. The $N(E)$ spectra resulting from the modeling of the two spectroscopic parameters $(\Psi, \Delta)$ are displayed in Fig. 2 which express the amplitude ratio and phase difference between p- and s-polarizations, respectively. In this figure, we present the obtained spectra for the binary alloy semiconductor $\mathrm{Ge}_{1-\mathrm{y}} \mathrm{Sn}_{\mathrm{y}}$ (top) and the ternary alloy $\mathrm{Ge}_{1-\mathrm{x} \text { - }}$ ${ }_{\mathrm{y}} \mathrm{Si}_{\mathrm{x}} \mathrm{Sn}_{\mathrm{y}}$ (bottom), where the composition of $\mathrm{Sn}$ has been measured by Energy Dispersive X-ray spectroscopy (EDX) and Rutherford backscattering spectrometry. ${ }^{32}$

\section{Theoretical calculations}

The calculation of the optical absorption of the coreshell nanowire structure is performed within the framework of the Lorenz-Mie scattering formalism ${ }^{33}$ adapted to a cylindrical geometry. The CSNW is modeled as an infinitely long coaxial cylinder (the diameter $d$ is at least 10 times smaller than the length), which has been well applied to analyze light absorption in various NWs. ${ }^{34-37}$ The CSNW has a total radius of $t+R_{c}$, where $t$ and $R_{c}$ are the shell thickness and the core radius, respectively. The nanowire, placed in vacuum, is illuminated by a plane wave of a wavevector, $\boldsymbol{k}_{\text {in }}$, perpendicular to the NW axis, as depicted in Fig. S1 in the 
(a)

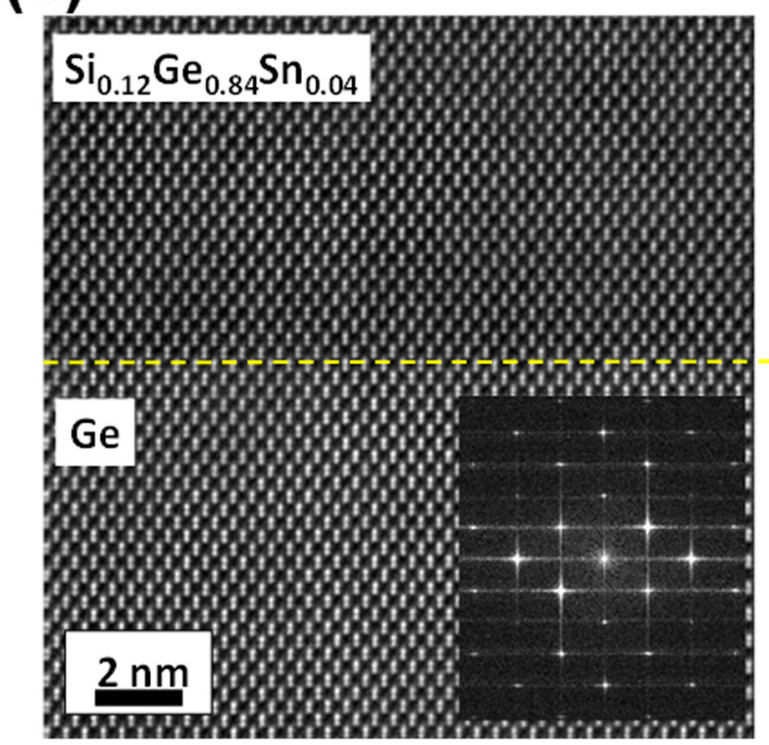

(c)
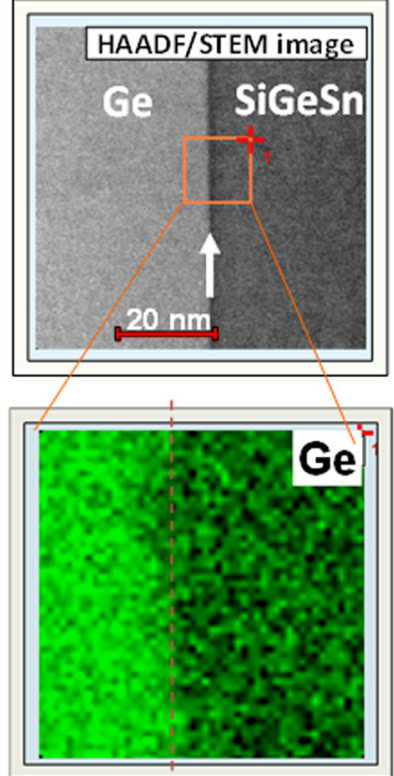
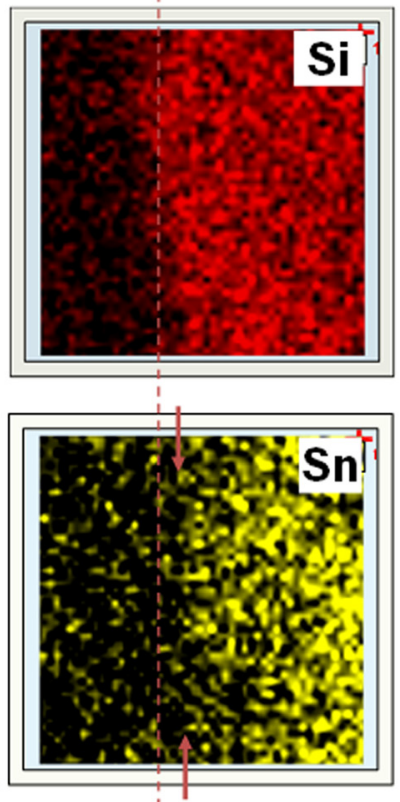

(b)

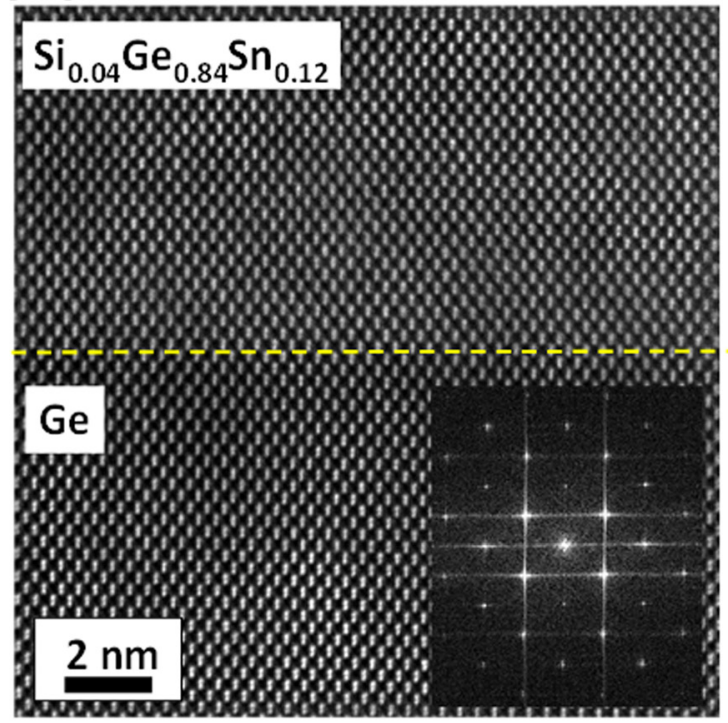

(d)
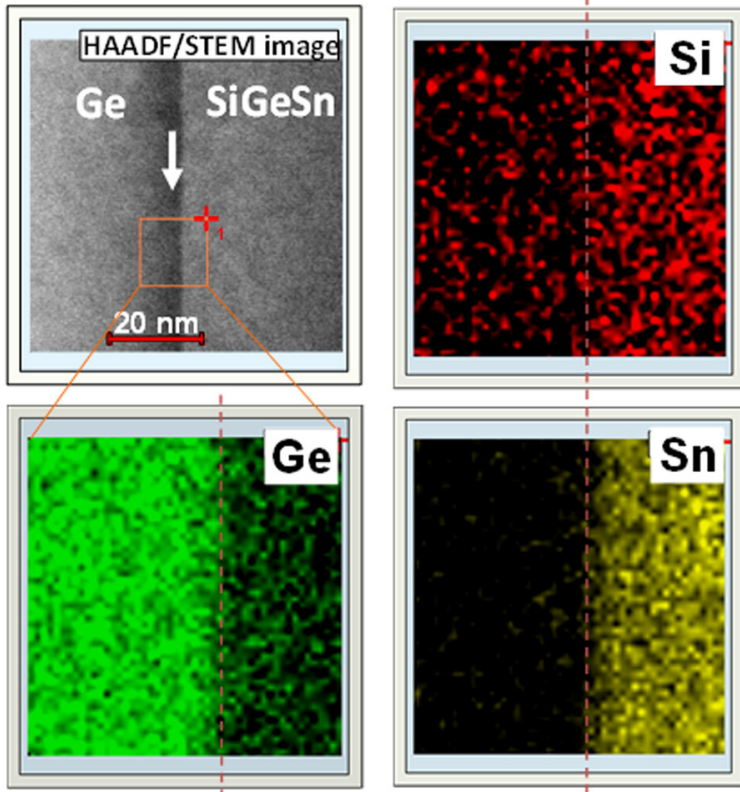

FIG. 1. High Angle Annular Dark Field Scanning Transmission Electron Microscopy (HAADF/STEM) image of $\mathrm{Ge}_{0.84} \mathrm{Si}_{0.12} \mathrm{Sn}_{0.04}\left(\right.$ a) and Ge $0{ }_{0.84} \mathrm{Si}_{0.04} \mathrm{Sn}_{0.12}$ (b) layers grown on Ge virtual substrates. Note the absence of dislocations or extended defects in the ternary layer or at the interface. The corresponding diffraction patterns measured at the interface are shown in inset figures in (a) and (b), confirming the high crystallinity and the absence of Sn precipitates. Low magnification HAADF/STEM images and EDX maps of $\mathrm{Si}$, Ge, and $\mathrm{Sn}$ in $\mathrm{Ge}_{0.84} \mathrm{Si}_{0.12} \mathrm{Sn}_{0.04}$ (c) and $\mathrm{Ge}_{0.84} \mathrm{Si}_{0.04} \mathrm{Sn}_{0.12}$ (d) layers.

supplementary material. Furthermore, we have fixed the wavelength range to $300-1100 \mathrm{~nm}$ covering the visible and NIR range of the solar spectrum (AM1.5G). ${ }^{38}$ The complex refractive index of $\mathrm{Ge}_{1-\mathrm{y}} \mathrm{Sn}_{\mathrm{y}}$ and $\mathrm{Ge}_{1-\mathrm{x}-\mathrm{y}} \mathrm{Si}_{\mathrm{x}} \mathrm{Sn}_{\mathrm{y}}$ ternary alloys was extracted from spectroscopic ellipsometry measurements outlined above. Here, we will focus on Sn-rich alloys $\mathrm{Ge}_{0.88} \mathrm{Sn}_{0.12}$ and $\mathrm{Ge}_{0.84} \mathrm{Si}_{0.04} \mathrm{Sn}_{0.12}$ because their composition is very close to those predicted for direct bandgap semiconductors with direct gaps of $0.49 \mathrm{eV}$ (Ref. $39)$ and $0.46 \mathrm{eV},{ }^{23}$ respectively. The NW far-field optical response is characterized by two dimensionless quantities: the absorption efficiency $Q_{a b s}$ and the scattering efficiency $Q_{s c a}$ are as follows:

$$
Q_{a b s(s c a t)}=\frac{Q_{a b s(s c a)}^{T M}+Q_{a b s(s c a)}^{T E}}{2},
$$

where $Q_{a b s(s c a)}^{T E}$ and $Q_{a b s(s c a)}^{T M}$ are the absorption (scattering) efficiencies for transverse electrical TE (the electric field is perpendicular to the NW axis) and transverse magnetic TM (the electric field is parallel to the NW axis) polarisations, respectively.

These quantities correspond to the ratio of the absorption $\left(C_{a b s}\right)$ and scattering $\left(C_{s c a}\right)$ cross sections to the geometrical cross section $C_{\text {geo }}$ of the NW, respectively. ${ }^{33}$ The cross section is defined as a fictive area around the illuminated object. As soon as a light beam hits this area, the interaction occurs. If we 


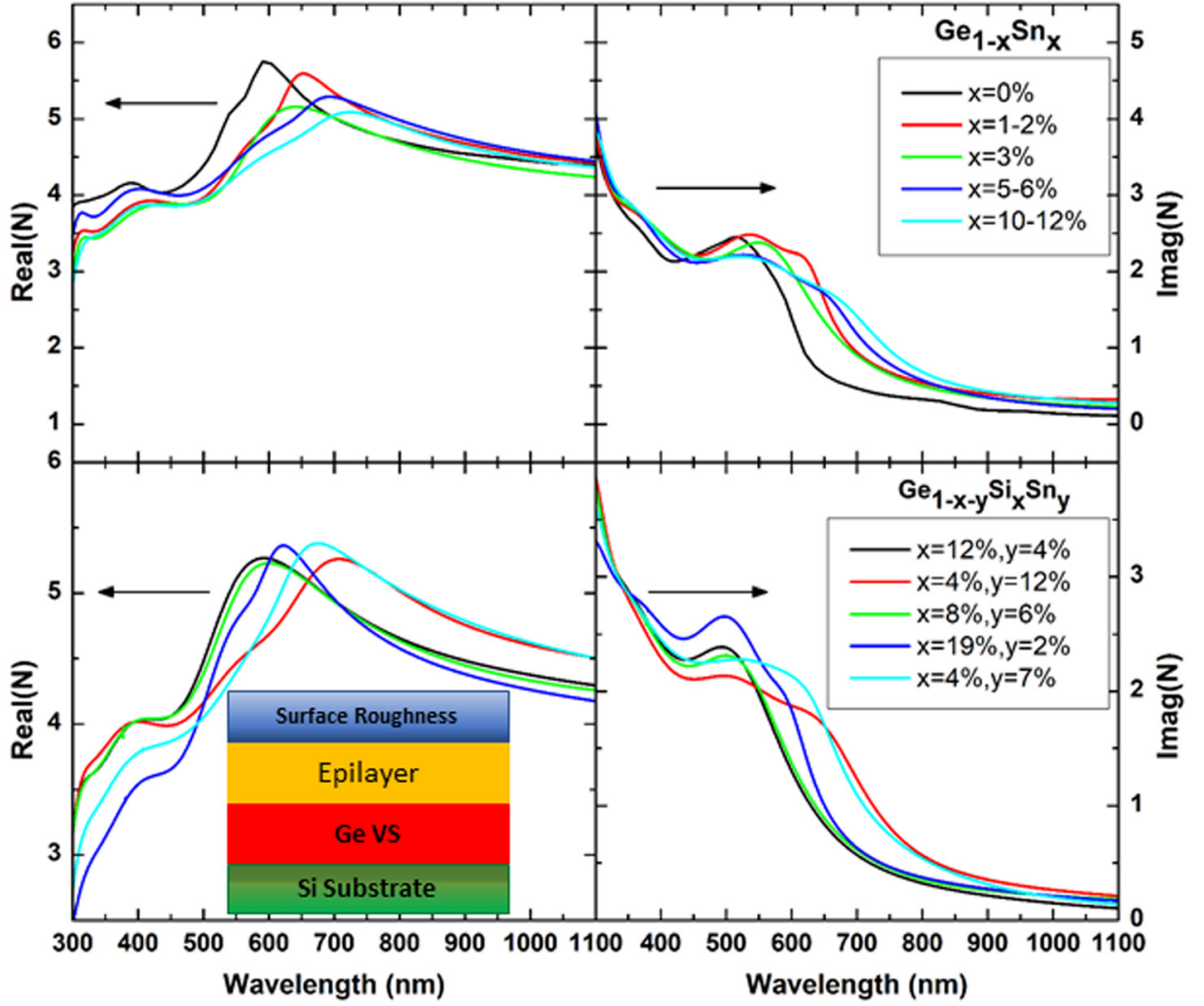

FIG. 2. The complex refractive index constant $N(\lambda)$ spectra of the $\mathrm{Ge}_{1-\mathrm{x}} \mathrm{Sn}_{\mathrm{x}}$ binary semiconductor alloy as a function of the wavelength for different $\mathrm{Sn}$ compositions (top) and the $\mathrm{Ge}_{1-\mathrm{x}-\mathrm{y}}$ $\mathrm{Si}_{\mathrm{x}} \mathrm{Sn}_{\mathrm{y}}$ ternary alloy as a function of the wavelength for different $\mathrm{Si}$ and $\mathrm{Sn}$ compositions obtained from the spectroscopic ellipsometry measurement (bottom). The optical properties of the Ge $(001)$ substrate $(x=0 \%)$ in the $\mathrm{Ge}_{1-\mathrm{x}} \mathrm{Sn}_{\mathrm{x}}$ binary are taken from the study by Palik. ${ }^{56}$ The inset shows the multilayer model used to extract the optical properties (Sec. S1 in the supplementary material). consider an ideal case where the absorption cross section $C_{a b s}$ of a hypothetical, perfectly absorbing black body is always equal to the geometrical area $A$ of the object, the absorption efficiency is therefore always equal to 1 . Now, for a system that is

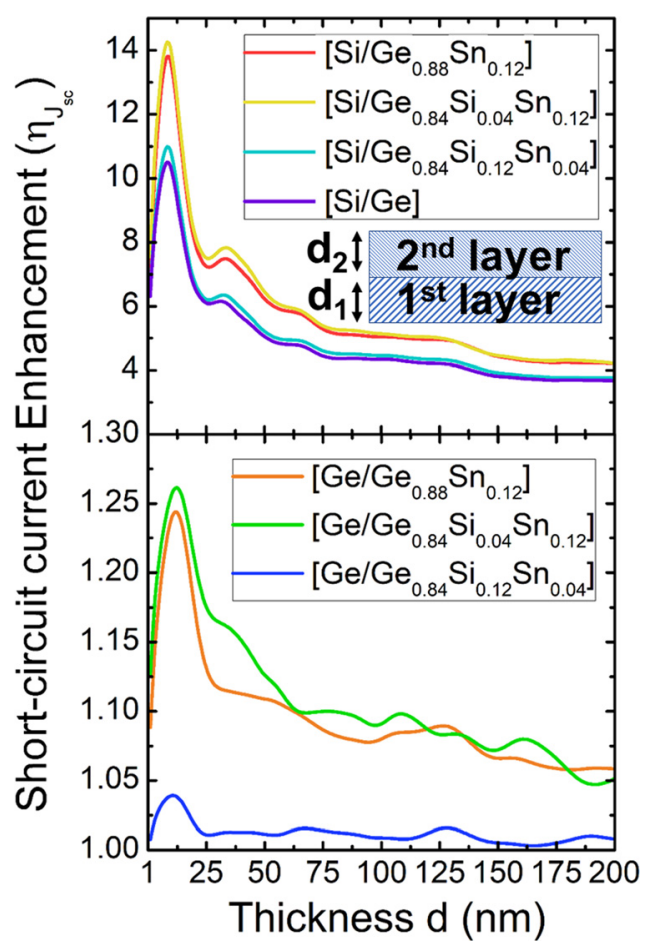

FIG. 3. Photocurrent enhancement for a bilayer structure having film thicknesses between 1 and $200 \mathrm{~nm}$ where the first layer of thickness $d_{1}$, shown in the inset, is either the $\mathrm{Si}$ or the Ge layer and where the top thin layer of thickness $d_{2}$ is $\mathrm{Ge}_{0.88} \mathrm{Sn}_{0.12}, \mathrm{Ge}_{0.84} \mathrm{Si}_{0.04} \mathrm{Sn}_{0.12}$, or $\mathrm{Ge}_{0.84} \mathrm{Si}_{0.12} \mathrm{Sn}_{0.04}$. We present here the short-current enhancement when $d=d_{1}+d_{2}$. The inset illustrates the studied thin-film structures. an imperfect absorber, the absorption efficiency $Q_{a b s}$ is between 0 and 1 within the limits of geometrical optics. Leaving these limits, when the structure is smaller than the illuminating wavelength $\lambda$, such as the case for the studied NWs (where the diameters are typically below $200 \mathrm{~nm}$ ), the absorption efficiencies $Q_{a b s}$ can exceed unity. ${ }^{33}$ This can be interpreted by the higher absorption cross section $C_{a b s}$ as compared to the geometrical cross section $C_{g e o}$. In other words, the NW can collect light from an area much bigger than its geometrical area $A .^{12,34,40,41}$

In the following, we briefly present the key equations under the Lorenz-Mie framework, allowing the quantification of light absorption by CSNW structures. Under unpolarised illumination, the NW far-field optical response is the average of the absorption efficiencies between TE and TM modes, and it is given by Eq. (1).

In addition, the absorption efficiency is deduced from the difference of the extinction and scattering efficiencies. Thus, we have

$$
Q_{a b s}^{T M}=Q_{e x t}^{T M}-Q_{s c a}^{T M} ; \quad Q_{a b s}^{T E}=Q_{e x t}^{T E}-Q_{s c a}^{T E} .
$$

These efficiencies are explicitly given by

$$
\begin{aligned}
& Q_{\text {ext }}^{T E}=\frac{2}{r k_{0}} \operatorname{Re}\left\{\sum_{n=-\infty}^{\infty} a_{n}\right\} ; \quad Q_{\text {ext }}^{T M}=\frac{2}{r k_{0}} \operatorname{Re}\left\{\sum_{n=-\infty}^{\infty} b_{n}\right\}, \\
& Q_{s c a}^{T E}=\frac{2}{r k_{0}} \operatorname{Re}\left\{\sum_{n=-\infty}^{\infty}\left|a_{n}\right|^{2}\right\} ; \quad Q_{\text {sca }}^{T M}=\frac{2}{r k_{0}} \operatorname{Re}\left\{\sum_{n=-\infty}^{\infty}\left|b_{n}\right|^{2}\right\},
\end{aligned}
$$

where $r$ is the radial dimension of a NW, which is equal to $R_{c}+t$, as shown in the inset of Fig. 4. Note that the NW core and the shell are composed of different semiconductors that 
can contribute to light absorption. Finally, $a_{n}$ and $b_{n}$ can be readily obtained by solving Maxwell's equations with the appropriate boundary conditions ${ }^{33,42}$ at the core/shell interface and shell/air interfaces. We present in the supplementary material (Sec. S2) a new detailed treatment for the TE and TM modes for a random incidence angle. In addition, to benchmark the Lorenz-Mie scattering code, we validated our calculation by studying the scattering efficiency of the SiNW system and comparing our results with what has been experimentally reported in the literature. The full benchmark study is presented in Sec. S3 in the supplementary material.

To implement the Lorenz-Mie scattering formalism, we developed a MATLAB ${ }^{\circledR}$ code to solve the Maxwell equations in all of the aforementioned NW systems (NWs and CSNWs). Furthermore, we developed a Full-Vector, FiniteDifference, complex mode solver in order to find the effective refractive index of the CSNW structure based on the work presented in Ref. 41. Calculations were carried out on a polycarbonate (PC) equipped with a single Intel Core 4 Quad 2.40 GHz processor equipped with 32GB of RAM.

\section{RESULTS AND DISCUSSION}

We investigated different CSNWs, including $\mathrm{Si} / \mathrm{Ge}_{1-\mathrm{y}} \mathrm{Sn}_{\mathrm{y}}$, $\mathrm{Si} / \mathrm{Ge}_{1-\mathrm{x}-\mathrm{y}} \mathrm{Si}_{\mathrm{x}} \mathrm{Sn}_{\mathrm{y}}, \mathrm{Ge} / \mathrm{Ge}_{1-\mathrm{y}} \mathrm{Sn}_{\mathrm{y}}$, and $\mathrm{Ge} / \mathrm{Ge}_{1-\mathrm{x}-\mathrm{y}} \mathrm{Si}_{\mathrm{x}} \mathrm{Sn}_{\mathrm{y}}$. First, before investigating the solar absorption enhancement in CSNWs, we present in Fig. 3 the calculated short-circuit current density enhancement of a bilayer thin film structure of equal thickness $d_{1}=d_{2}$ composed of different group IV semiconductor alloys, mainly, $\mathrm{Si} / \mathrm{Ge}, \mathrm{Si} / \mathrm{Ge}_{0.88} \mathrm{Sn}_{0.12}, \mathrm{Ge} /$ $\mathrm{Ge}_{0.88} \mathrm{Sn}_{0.12}, \mathrm{Si} / \mathrm{Ge}_{1-\mathrm{x}-\mathrm{y}} \mathrm{Si}_{\mathrm{x}} \mathrm{Sn}_{\mathrm{y}}$, and $\mathrm{Ge} / \mathrm{Ge}_{1-\mathrm{x}-\mathrm{y}} \mathrm{Si}_{\mathrm{x}} \mathrm{Sn}_{\mathrm{y}}$ with $(\mathrm{x}, \mathrm{y})=(12 \%, 4 \%)$ and $(4 \%, 12 \%)$. The short-current density was evaluated using Eq. (5), and the absorption efficiency for the single and double layers was calculated using the Transfer Matrix Method (TMM) described extensively in Ref. 43 under a TM polarization and normal incidence. Figure 3 demonstrates a significant enhancement in the photocurrent when $\mathrm{Si}$ and Ge are capped by an Sn-containing binary or ternary layer, relative to a single $\mathrm{Si}$ and Ge layer of the same thickness. On the one hand, this enhancement is more pronounced for Si based substrates where a $\sim 9 \mathrm{~nm}$-thick $\mathrm{Ge}_{0.88} \mathrm{Sn}_{0.12}$ or $\mathrm{Ge}_{0.84} \mathrm{Si}_{0.04} \mathrm{Sn}_{0.12}$ capping layer yields a $\sim 14$-fold increase in photocurrent as compared to bare Si. Moreover, we can conclude by comparing the short-circuit current enhancement of $\mathrm{Si} / \mathrm{Ge}$ and $\mathrm{Si} / \mathrm{Ge}_{0.99} \mathrm{Sn}_{0.12}$ that these large enhancement factors are a result of the addition of the unique optical properties of the Sn alloy rather of the small bandgap of Ge. On the other hand, adding Sn-rich binary or ternary alloys $\left(\mathrm{Ge}_{0.88} \mathrm{Sn}_{0.12}\right.$ or $\mathrm{Ge}_{0.84} \mathrm{Si}_{0.04} \mathrm{Sn}_{0.12}$ ) on a Ge substrate seems to affect less the

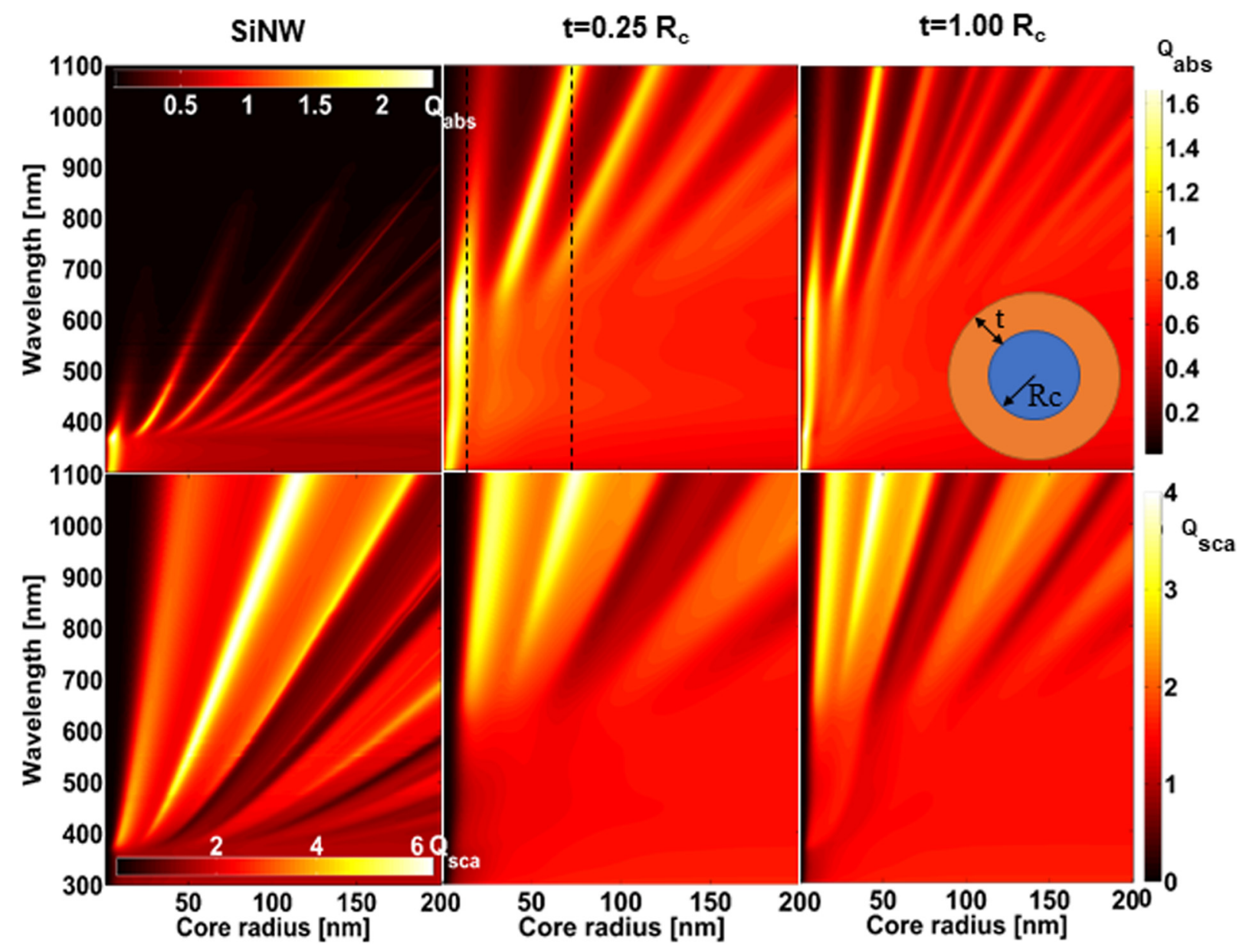

FIG. 4. Unpolarized absorption efficiency $\mathrm{Q}_{\mathrm{abs}}$ (top) and unpolarized scattering efficiency $\mathrm{Q}_{\text {sca }}$ (bottom) of $\mathrm{Si} / \mathrm{Ge}_{0.88} \mathrm{Sn}_{0.12} \mathrm{CSNWs}$ surrounded by air as a function of the core radius $\left(R_{c}\right)$ and the incident light wavelength for two different shell thicknesses: $t=R_{c} / 4$ and $t=R_{c}$. For comparison, SiNW absorption and scattering efficiencies are also shown. The three black-dashed lines indicate the selected radii: on-resonance (at $\left.R_{c}=8 \mathrm{~nm}\right)$ and off-resonance (at $\left.R_{c}=60 \mathrm{~nm}\right)$. The inset shows a cross-section of the geometry of the CSNW structure, with the geometrical parameters. 
short-circuit current enhancement, as compared to its Si counterparts, with an increase of $\sim 25 \%$ at $11 \mathrm{~nm}$ thickness. It is important to note that the richer in $\mathrm{Sn}$ the samples are the higher the short-circuit current enhancement is, and we will investigate later if this behavior holds for CSNW structures and compare the short-current enhancement of CSNWs to thin films. It is worth mentioning that in a conventional planar structure, increased reflection or backscattering from the material's front surface decreases light absorption. Thus, changing the geometry from thin films to 1D subwavelength NWs would increase scattering, which is an indicative of an enhanced optical antenna effect, which increases both scattering and absorption in the NW.

Second, Lorenz-Mie calculation is used to generate 2D maps of absorption and scattering efficiencies as a function of the incident wavelength and of the NW core radius for the $\mathrm{Si} / \mathrm{GeSn}$ and $\mathrm{Ge} / \mathrm{GeSn}$ structures. We start by examining the maps of absorption and scattering efficiencies of CSNWs with a shell made of the binary alloy GeSn and a core made of $\mathrm{Si}$ or Ge as displayed in Figs. 4 and 5 at two shell thicknesses $t=R_{c} / 4$ and $t=R_{c}$, respectively. Figure 4 exhibits the absorption (top) and scattering (bottom) efficiencies of the $\mathrm{Si} / \mathrm{Ge}_{0.88} \mathrm{Sn}_{0.12} \mathrm{CSNW}$, whereas Fig. 5 shows the corresponding results for the $\mathrm{Ge} / \mathrm{Ge}_{0.88} \mathrm{Sn}_{0.12} \mathrm{CSNW}$. Moreover, the figures also display the absorption and scattering efficiencies for SiNWs and GeNWs, thus highlighting the effect of the Sn-containing shell on the absorption and scattering efficiencies. For wavelengths larger than $\sim 550 \mathrm{~nm}$, $Q_{\text {sca }}$ shows distinct features in terms of bright whiskers for both TE and TM polarizations (not shown in Figs. 4 and 5 but can easily be inferred from the unpolarised 2D map because $\left.Q_{s c a}^{U n p}=\left(Q_{s c a}^{T E}+Q_{s c a}^{T M}\right) / 2\right)$. The slope of the whiskers decreases with the increasing core radius $R_{c}$ and decreasing wavelengths. A possible way to explain these whiskers of the scattering efficiency is by considering the theoretical expression of $Q_{s c a}$ given by the Lorenz-Mie formalism for a CSNW (formulas of the scattering coefficients are given in the supplementary material Sec. S2). In fact, since the complex refractive index of $\mathrm{Ge}_{0.88} \mathrm{Sn}_{0.12}$ shows a weak dependence on the wavelength for $\lambda>550 \mathrm{~nm}$ (see Fig. 2), the scattering coefficients are proportional to the size parameter $x_{j(j \in\{\text { shell,core }\})} \propto R_{c} / \lambda$. Thus, $Q_{\text {sca }}$ is nearly constants along straight lines in the $\left(\lambda, R_{c}\right)$-plane. The same behaviour is observed for scattering efficiency $Q_{\text {sca }}$ for both CSNW systems with a $\mathrm{Ge}_{0.88} \mathrm{Sn}_{0.12}$ shell, but the whiskers are observed in different regions.

Next, we study thoroughly the effect of the shell thickness on the absorption and scattering efficiencies. By examining the data obtained for the $\mathrm{Si} / \mathrm{Ge}_{0.88} \mathrm{Sn}_{0.12} \mathrm{CSNW}$ (Fig. 4), two important observations emerge. First, the whisker

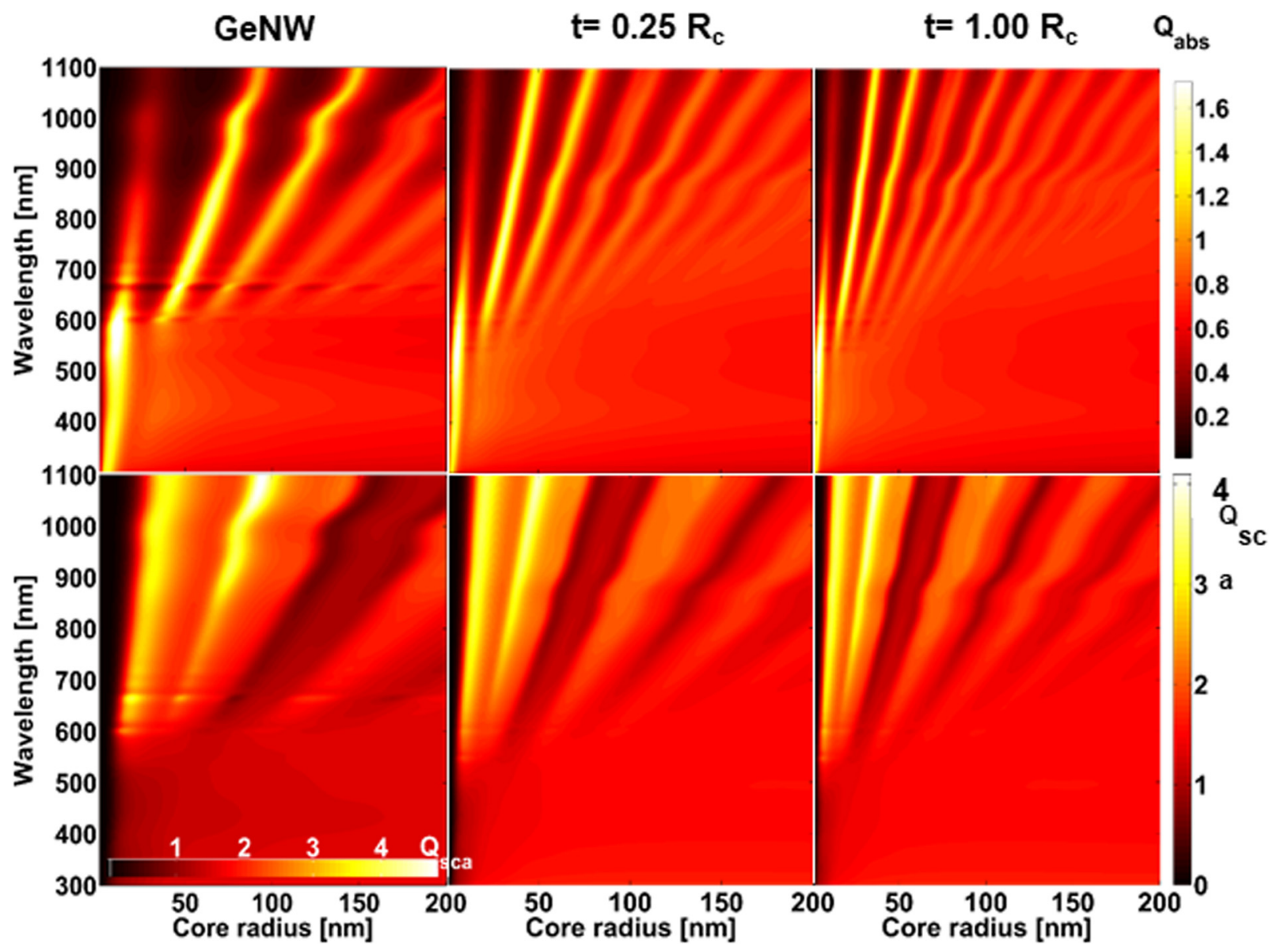

FIG. 5. Unpolarized absorption efficiency $\mathrm{Q}_{\text {abs }}$ (top) and unpolarized scattering efficiency $\mathrm{Q}_{\text {sca }}$ (bottom) of Ge/Ge ${ }_{0.88} \mathrm{Sn}_{0.12} \mathrm{CSNWs}$ surrounded by air as a function of the core radius $\left(R_{c}\right)$ and the incident light wavelength for two different shell thicknesses: $t=R_{c} / 4$ and $t=R_{c}$. For comparison, GeNW absorption and scattering efficiencies are also shown. 
resonance distribution shows an evolution as a function of the core and shell dimensions. Particularly, the whisker distribution with increasing GeSn shell thickness $t$ will move toward higher wavelengths. In fact, for a fixed core radius $\left(R_{c}=60 \mathrm{~nm}\right)$ and an increasing shell thickness, Figs. S3(a) and $\mathrm{S} 3(\mathrm{~b})$ in the supplementary material qualitatively shows this behavior where the effect of the geometrical parameters on the leaky resonant modes is shown. In fact, by focusing on $\mathrm{TM}_{41}$, we deduce that increasing the shell thickness will induce a redshift in the leaky mode resonance. Besides, the higher leaky modes are located at a smaller wavelength, whereas the fundamental mode $T M_{01}$ is located near the midinfrared range. Three resonant Mie absorption peaks were observed at $720.6,932,733$, and $1073 \mathrm{~nm}$ for a shell thickness equal to $0.5 \times R_{c}$ [green curve in Fig. S3(a) in the supplementary material]. Incident electromagnetic waves having a specific wavelength, $\lambda$, are trapped along the periphery of core/shell nanowires similar to whispering gallery modes in micrometer-scale resonators. The resonant field intensity is built up inside the nanowire, and then, the confined mode leaks due to the small size of nanowires compared to the wavelength of the light $(\lambda>300 \mathrm{~nm}$ and $d<200 \mathrm{~nm}$ ). The leakage effect is observable in the electric field profile shown in Fig. S3(b) in the supplementary material for the fundamental leaky mode $T M_{01}$ and a core radius of $8 \mathrm{~nm}$ and a shell thickness equal to $0.25 \times R_{c}$. To quantitatively analyze the leaky mode evolution $v s$. the core radius, we numerically solve the Helmholtz-Eigen equation by using a full-vector, finite difference (FVFD) approach coupled with a perfectly matched layer (PML) boundary condition terminated with a zero boundary condition ${ }^{44}$ to find the complex effective refractive index $n_{\text {eff }}$ of the CSNW. Each complex solution is the eigenvalue of a specific leaky mode. Leaky modes can be characterized by an azimuthal mode number, $m$, which indicates an effective number of wavelengths around the wire circumference and a radial order number, $l$, describing the number of radial field maxima within the cylinder (for instance, $\mathrm{TM}_{m l}$ ). ${ }^{40}$ The leaky mode resonances, $\mathrm{TE}_{m l}$ and $\mathrm{TM}_{m l}$, have previously been shown to correspond to peaks in the scattering and absorption spectra of nanowires. ${ }^{40,45}$ The real part of $n_{\text {eff }}$ is indicative of the resonant wavelength and propagation constant, and the imaginary part is indicative of the radiative loss of the mode, which for a lossy medium is also a measure of the absorptive loss. Thus, we can estimate the resonant scattering wavelength from $m \lambda / n_{\text {eff }}=\pi d$, where $m=1,2, \ldots, \lambda$ is the free space wavelength of incident light, $n_{\text {eff }}$ is the effective refractive index, and $d$ is the diameter of the nanowire. For instance, the nanowire with a $120 \mathrm{~nm}$ diameter $\left(R_{c}=60 \mathrm{~nm}\right)$ exhibits an absorption peak at $1073 \mathrm{~nm}$ as shown in Fig. S4(a). By using the above formula, we obtain $n_{\text {eff }}=2.862$ (for $\mathrm{m}=1$ ), which is close to the refractive index of the Si core (3.55) at this wavelength. Using the FVFD approach, we estimate the effective refractive index to be 3.13656 . Such a result reveals two important features: the optical antenna effect is maximized at each resonance and the scattering and absorption spectra are highly structured with multiple discrete peaks, and this optical antenna effect is enhanced by decreasing the NW core radius. As shown in Figs. 4 and 5 (bottom), when the core radius is smaller or the wavelength of the incident light is longer, the scattering efficiency increases. The data presented in Figs. 4 and 5 clearly demonstrate the ability to tune the absorption and scattering of light using CSNWs by controlling either the NW radius or the light wavelength in the visible and especially the NIR range where the scattering efficiency is maximised. The second important element affecting the absorption efficiency is the presence of localized resonant modes. Similar observations were reported in different systems: GaN nanowire cavity, ${ }^{46}$ hydrogenated amorphous silicon a-Si:H core with a dielectric shell, ${ }^{13}$ and polycarbonate (PC)-polyvinylidene difluoride (PVDF) CSNW. ${ }^{47}$ Interestingly, it is possible to engineer the resonant properties inside a CSNW by tuning the core radius and/or the shell thickness in a way that light absorption can be enhanced in resonance regions, the so-called the leaky-mode resonance (LMR) enhancement. This effect will be explored in order to optimize the morphology of CSNWs to achieve efficient light absorption. For this, in the following, we define the optimal core radius, shell thickness, and the shell type (be it $\mathrm{Ge}_{1-\mathrm{y}} \mathrm{Sn}_{\mathrm{y}}$ binary alloy or $\mathrm{Ge}_{1-\mathrm{x}-\mathrm{y}} \mathrm{Si}_{\mathrm{x}} \mathrm{Sn}_{\mathrm{y}}$ ternary alloy). The absorption behavior can be understood by means of the Fano-resonance effect $^{48}$ that is an interference effect arising from the incident light and the localized reemitted leaky-mode resonance light due to the subwavelength size of NWs. Moreover, in order to quantify the absorption of different CSNW structures across the solar spectrum, we calculate the ultimate efficiency $\eta_{\text {eff }} 49$ defined assuming that each absorbed photon with energy greater than the bandgap produces a single electron-hole pair with energy $h c / \lambda_{g}$, where $\lambda_{g}$ is the wavelength corresponding to the minimum bandgap between the core and the shell. Note that unstrained $\mathrm{Si}$ and Ge have an indirect bandgap of $1.12 \mathrm{eV}$ and $0.66 \mathrm{eV}$, respectively, whereas the unstrained $\mathrm{Ge}_{0.88} \mathrm{Sn}_{0.12}$ is a direct gap semiconductor having a gap of $0.49 \mathrm{eV}^{23} \eta_{\text {eff }}$ is given by

$$
\eta_{\text {eff }}=\frac{\int_{0.3 \mu m}^{\lambda_{g}} F_{s}(\lambda) Q_{a b s}\left(\lambda, r_{c}, t\right) \frac{\lambda}{\lambda_{g}} d \lambda}{\int_{0.3 \mu m}^{4 \mu m} F_{s}(\lambda) d \lambda},
$$

where $\lambda$ is the wavelength, $F_{s}(\lambda)$ is the spectral irradiance (power density in $\mathrm{W} \mathrm{m}^{-2} \mathrm{~nm}^{-1}$ ) of the ASTM AM1.5G direct normal and circumsolar spectrum, ${ }^{38} Q_{a b s}\left(\lambda, R_{c}, t\right)$ is the spectral absorption efficiency evaluated with the LorenzMie scattering formalism, and $\lambda_{g}$ is the wavelength corresponding to the minimum bandgap between the core and the shell. Special care is needed when evaluating the integrals in Eq. (4) due to the non-uniformity of the spectral range in the ASTM data. To solve this issue, we simply used a Piecewise cubic Hermite interpolating polynomial to interpolate the optical properties between 300 and $1100 \mathrm{~nm}$ to match the ASTM spectral wavelength steps. For instance, if we consider the $\mathrm{Si} / \mathrm{GeSn} \mathrm{CSNW}$, then $\lambda_{g}=2.583 \mu \mathrm{m}$. The ultimate efficiency can be linked to the maximum short-circuit current, $J_{s c}$, by assuming an ideal carrier collection efficiency where every photogenerated carrier reaches the electrodes and contributes to photocurrent. Under this condition, we write 


$$
\begin{aligned}
J_{s c} & =\frac{q}{h c} \int_{0.3 \mu \mathrm{m}}^{\lambda_{g}} F_{s}(\lambda) Q_{a b s}\left(\lambda, R_{c}, t\right) \lambda d \lambda \\
& =0.0726 \times \lambda_{g} \eta_{e f f}\left[\mathrm{~mA} / \mathrm{cm}^{2}\right],
\end{aligned}
$$

where $q$ is the elementary charge. However, because $Q_{a b s}$ can reach values greater than unity, as explained above, the integrated solar absorption cannot truly be considered as the real ultimate photocurrent intensity or the short-circuit current density. Nevertheless, $J_{s c}$ is a figure of merit proportional to the actual photocurrent intensity, very useful to compare to the absorption efficiency capability of the studied quantum structures. $^{13}$

The photocurrent enhancement is defined as the ratio of the short-circuit current of a two-layer stack to the shortcircuit current of a Si or Ge film. For instance, the enhancement of the photocurrent of the $\mathrm{Si} / \mathrm{Ge}_{0.88} \mathrm{Sn}_{0.12}$ thin film [red line in Fig. 3(a)] is evaluated by calculating the ratio

$$
\eta_{J_{s c}}=\frac{J_{s c}^{S i / G e S n}}{J_{s c}^{S i B u l k}}(\text { Bulk }) \quad \text { or } \quad \eta_{J_{s c}}=\frac{J_{s c}^{S i / G e S n C S N W}}{J_{s c}^{S i N W}}(N W),
$$

where $J_{s c}^{S i / G e S n}$ and $J_{s c}^{S i B u l k}$ are the photocurrents generated in the $\mathrm{Si} / \mathrm{Ge}_{0.88} \mathrm{Sn}_{0.12}$ stack and $\mathrm{Si}$ thin film, respectively. To quantify the short-circuit current enhancement for thin films or nanowire structures, the reference short-circuit current $\left(J_{s c}^{S i B u l k}\right.$ or $\left.J_{s c}^{S i N W}\right)$ is evaluated following this procedure: (i) for thin films $\mathrm{A} / \mathrm{B}$, the short-circuit current is evaluated for a thin-film slab of thickness $d_{A}+d_{B}$ composed only from material $\mathrm{A}$, whereas (ii) for the $\mathrm{A} / \mathrm{B} \mathrm{CSNW}$ structure, the short-circuit current is calculated for a single nanowire composed of material $\mathrm{A}$ and having a core radius of $R_{c}+t$, where $t$ is the shell thickness of the B layer in the A/B CSNW structure. $\eta_{J_{s c}}$ displays a few peaks attributed to Fabry-Pérot resonance which is much weaker than LMR in NWs.

To investigate the absorption enhancement in CSNWs, we evaluate the integrated solar absorption efficiency as a function of the NW dimensions for the four structures proposed above and analyzed in Fig. 6. Figure 6(a) displays the variation of the solar absorption efficiency as a function of the shell thickness $(t)$ and the core radius $\left(R_{c}\right)$. We recognize the whiskered features, similar to the absorption efficiency presented in Figs. 3 and 4, attributed to LMR modes. Interestingly, the 2D photocurrent enhancement maps of $\mathrm{Si} /$ $\mathrm{Ge}_{0.88} \mathrm{Sn}_{0.12}$ and $\mathrm{Si} / \mathrm{Ge}_{0.84} \mathrm{Si}_{0.04} \mathrm{Sn}_{0.12} \mathrm{NW}$ structures show narrow regions $\left(R_{c}<56 \mathrm{~nm}\right.$ and $\left.t<40 \mathrm{~nm}\right)$ where an extreme enhancement of $J_{s c}$ is achieved, reaching an increase in 11-22-fold for $\mathrm{Si} / \mathrm{Ge}_{0.88} \mathrm{Sn}_{0.12}$ and 25-47-fold for $\mathrm{Si}$ / $\mathrm{Ge}_{0.84} \mathrm{Si}_{0.04} \mathrm{Sn}_{0.12}$ compared to a SiNW. Besides, from the maps of $\mathrm{Ge} / \mathrm{Ge}_{0.88} \mathrm{Sn}_{0.12}$ and $\mathrm{Ge} / \mathrm{Ge}_{0.84} \mathrm{Si}_{0.04} \mathrm{Sn}_{0.12}$, when the core radius is larger than the shell thickness $\left(R_{c}>t\right)$, we observe a maximum short-current enhancement of 7-fold compared to the GeNW system. The enhancement is governed by the LMR modes, where the highest enhancement occurs for a shell thickness below $8 \mathrm{~nm}$ and a core radius between 30 and $45 \mathrm{~nm}$. Table I summarizes the key results of the short-circuit current enhancement for the above CSNW structures.
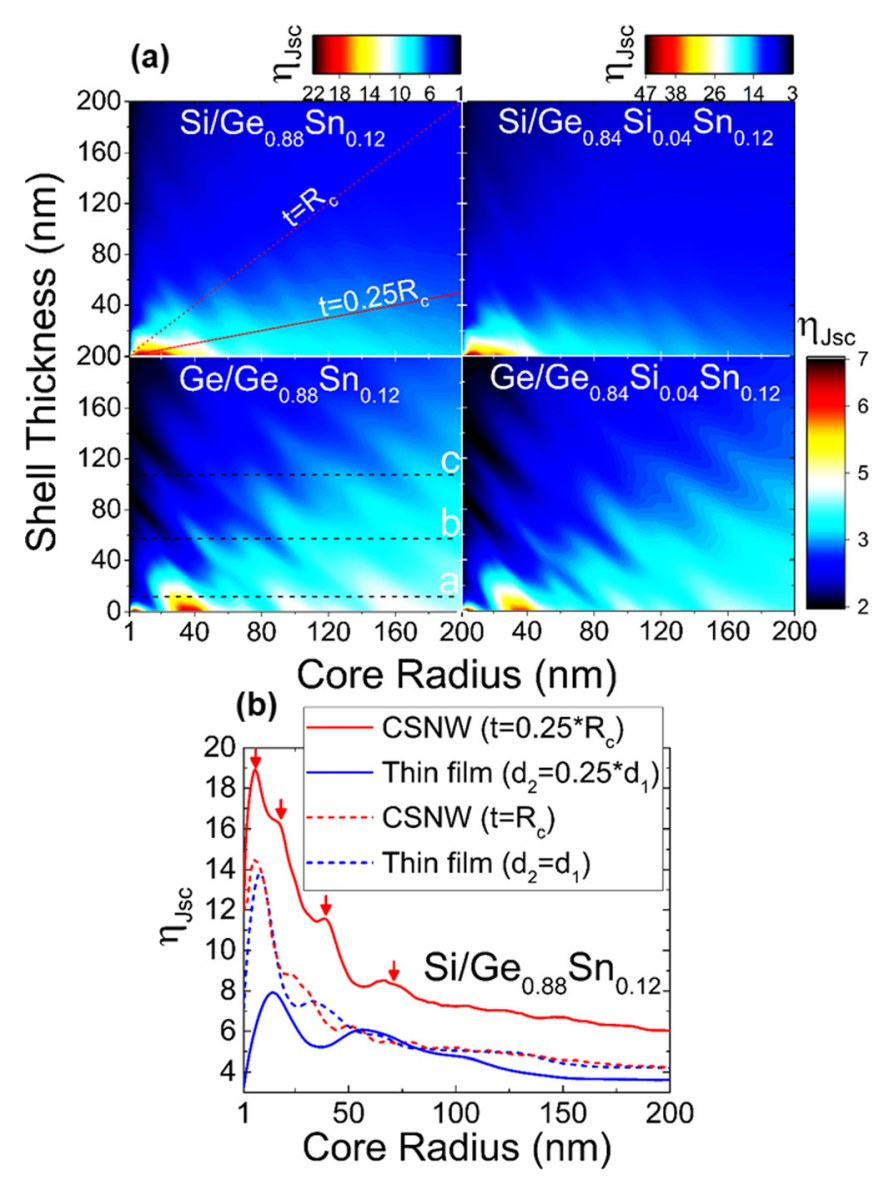

FIG. 6. (a) $2 \mathrm{D}$ short-circuit photocurrent enhancement $\eta_{J_{S c}}$ map as a function of the shell thickness $(t)$ and the core radius $\left(R_{c}\right)$ for the CSNW structures: from top-left to bottom-right: $\mathrm{Si} / \mathrm{Ge}_{0.88} \mathrm{Sn}_{0.12}, \mathrm{Si} / \mathrm{Ge}_{0.84} \mathrm{Si}_{0.04} \mathrm{Sn}_{0.12}, \mathrm{Ge} /$ $\mathrm{Ge}_{0.88} \mathrm{Sn}_{0.12}$, and $\mathrm{Ge} / \mathrm{Ge}_{0.84} \mathrm{Si}_{0.04} \mathrm{Sn}_{0.12} \cdot \eta_{J_{s c}}$ is equal to the absorption efficiency of the CSNW structure divided by the one for the core NW with a radius of $R_{c}+t$. The horizontal dashed lines represent 3 different shell thicknesses (line a $\rightarrow t=3 \mathrm{~nm}$; line $\mathrm{b} \rightarrow t=50 \mathrm{~nm}$, and line $\mathrm{c} \rightarrow t$ $=100 \mathrm{~nm}$ ) that will be analyzed more in detail in Fig. 7. Additionally, we present in panel (b) a line profile of the $\mathrm{Si} / \mathrm{Ge}_{0.88} \mathrm{Sn}_{0.12}$. CSNW $2 \mathrm{D}$ map, along two shell thickness $\left(t=[0.25,1] \times R_{c}\right)$ directions, shown as solid red and dashed-red lines, respectively, in panel (a). The red lines represent intensity profiles extracted from the 2D map in panel (a) following the directions $t=R_{c}$ and $t=R_{c} / 4$. We also present the short-current enhancement of the thin-film structure for 2 different top-layer thicknesses $\left(d_{2}=0.25 d_{1}\right.$ and $d_{2}=d_{1}$ ) for a $\mathrm{Si} / \mathrm{Ge}_{0.88} \mathrm{Sn}_{0.12}$ stack. The red arrows represent the peak core radius positions attributed to LMR.

Additionally, to quantitatively compare the short-current enhancement between the CSNW and thin film systems, we present in Fig. 6(b) the ratio $\eta_{J_{s c}}$ for $\mathrm{Si} / \mathrm{Ge}_{0.88} \mathrm{Sn}_{0.12}$ at two different shell thicknesses $\left(t=R_{c} / 4, R_{c}\right)$ for the CSNW (red curves) and two top layer thicknesses $\left(d_{2}=d_{1} / 4, d_{1}\right)$ for the thin films (blue curves). The short-circuit current

TABLE I. Core radius and shell thickness range corresponding to the optimal short-current enhancement (the highest value $\eta_{J_{s c}}$ ) for the four core/shell NW structures.

\begin{tabular}{lccccc}
\hline \hline & \multicolumn{3}{c}{$\mathrm{Si}$} & & \multicolumn{2}{c}{$\mathrm{Ge}$} \\
\cline { 2 - 3 } \cline { 5 - 6 } Core & $\mathrm{Ge}_{0.88} \mathrm{Sn}_{0.12}$ & $\mathrm{Ge}_{0.88} \mathrm{Si}_{0.04} \mathrm{Sn}_{0.12}$ & & $\mathrm{Ge}_{0.88} \mathrm{Sn}_{0.12}$ & $\mathrm{Ge}_{0.88} \mathrm{Si}_{0.04} \mathrm{Sn}_{0.12}$ \\
\hline $\mathrm{R}_{\mathrm{c}}(\mathrm{nm})$ & $3-31$ & $3-45$ & & $30-45$ & $30-42$ \\
$\mathrm{t}(\mathrm{nm})$ & $1-11$ & $1-14$ & & $1-8$ & $1-5$ \\
$\eta_{J_{s c}}$ & $13-22$ & $22-47$ & & 6 & 5.5 \\
\hline \hline
\end{tabular}


enhancement $\eta_{J_{s c}}$ is evaluated by calculating the ratio of $J_{s c}$ of the CSNW structure with a core radius $R_{c}$ and a shell thickness $t$ divided by $J_{s c}$ of the core NW with a core radius of $R_{c}+t$. We note that the $\eta_{J_{s c}}$ of the CSNW at $t=R_{c}$ is almost comparable to its counterparts for the thin film. Nevertheless, when we decrease the outer layer thickness from $t=R_{c}$ to $t=R_{c} / 4$ for the CSNW and from $d_{2}=d_{1}$ to $d_{2}=d_{1} / 4$ for the thin film, we notice a maximum shortcurrent enhancement from 14 to 19 in the CSNW and a decrease from 13 to 8 in the thin film. This is an interesting finding, suggesting that to increase light absorption in the CSNW, the shell thickness $t$ of the CSNW has to be inferior than the core radius $R_{c}$. Thus, on the one hand, decreasing the shell thickness from $R_{c}$ to $R_{c} / 4$ of the Si/GeSn CSNW will improve-on average-the short current by $45 \%$. On the other hand, decreasing the top layer thickness of the $\mathrm{Si}$ / GeSn thin film from $d_{1}$ to $d_{1} / 4$ will deteriorate-on average- the short-circuit current by $15 \%$.

To better illustrate the effect of the shell thickness on the photocurrent, data obtained for three different thicknesses $(t=3,50$, and $100 \mathrm{~nm})$ are selected from the 2D photocurrent maps [dashed lines labeled a, b, and c in Fig. 6(a)] and plotted in Fig. 7. The corresponding photocurrents are compared to those generated in the SiNW and GeNW. Note that the latter two have been extensively investigated in recent years, ${ }^{34,35,50,51}$ and our estimated photocurrents for the SiNW and GeNW are in full agreement with previous reports. More importantly, Fig. 7 clearly shows that the addition of a $\mathrm{SiGeSn}$ or a GeSn shell enhances significantly the photocurrent. For instance, the photocurrent enhancement has almost increased fivefold in $\mathrm{Si} / \mathrm{GeSn}$ and tenfold in $\mathrm{Si} /$ GeSiSn CSNW structures as compared to the SiNW (black curves in Fig. 7) at a shell thickness of $3 \mathrm{~nm}$ for core radii larger than $60 \mathrm{~nm}$. Also, when the shell thickness is equal to $3 \mathrm{~nm}$ [Fig. 7(a)], we obtain the highest value for $J_{s c}$ reaching up to $130 \mathrm{~mA} / \mathrm{cm}^{2}$ for the $\mathrm{Ge} / \mathrm{GeSn}$ structure at a core radius of $40 \mathrm{~nm}$. This is due to the presence of the $\mathrm{TM}_{11} / \mathrm{TE}_{01}$ leaky resonance mode at a core radius above $30 \mathrm{~nm}$ for all the studied NWs. We also notice an important improvement in $J_{s c}$ at smaller core radii which can reach $120 \mathrm{~mA} / \mathrm{cm}^{2}$ for $\mathrm{Ge} /$ $\mathrm{GeSn}, \mathrm{Ge} / \mathrm{GeSiSn}$, and $\mathrm{Si} / \mathrm{GeSiSn}$ structures for a $3 \mathrm{~nm}$-thick shell. Increasing the shell thickness will contribute to a deterioration of the short-circuit current, as it can be seen from Figs. 7(b) and 7(c) and has been shown from the aforementioned analysis of Fig. 6(b). Additionally, when panels (b) and (c) in Fig. 7 are compared with each other, it shows that there is relatively little difference between panels (b) and (c) in absolute values, suggesting a similar behavior for a shell thickness greater than $50 \mathrm{~nm}$. This can be deduced from the top left panel in Fig. 6(a). This extreme enhancement at a very small core radius $\left(R_{c}=7 \mathrm{~nm}\right)$ and shell thickness $(t=3 \mathrm{~nm})$ is due to the $\mathrm{TM}_{01}$ leaky resonance mode which is shown by the near-field profile inset in Fig. 7.

The fact that the photocurrent enhancement is practically independent of the core radius above $\sim 100 \mathrm{~nm}$ is an interesting result, suggesting that the generated photocurrent can be tuned through a simple control of the shell thickness rather than the core radius, thus providing more flexibility in the fabrication process. However, to ensure the integration of these structures in photonic devices, it is important to also optimize the efficiency of charge collection, which depends on the minority carrier lifetime, lattice defects, doping, contact quality, and design.

In addition, to further investigate the optimal CSNW geometry for light absorption, we defined a dimensionless parameter, $\eta_{a b s}$, as the ratio of the absorption efficiency of the CSNW to that of a pure NW (SiNW or GeNW) with a core radius of $R_{c}+t$ equal to its CSNW counterparts. For instance, if we consider the structure $\mathrm{Si} / \mathrm{GeSn}$, the absorption enhancement factor is defined as

$$
\eta_{a b s}\left(r_{c}, t, \lambda\right)=\frac{Q_{a b s}^{S i / G e S n}}{Q_{a b s}^{S i N W}} .
$$

If $\eta_{a b s}$ takes values larger than unity, then we conclude that light is absorbed efficiently by the CSNW structure as compared to the SiNW or the GeNW. The higher the value of $\eta_{a b s}$ is the more efficient absorber the CSNW is.

The enhancement of light absorption and photocurrent is due to the plurality of spectrally separated LMR supported

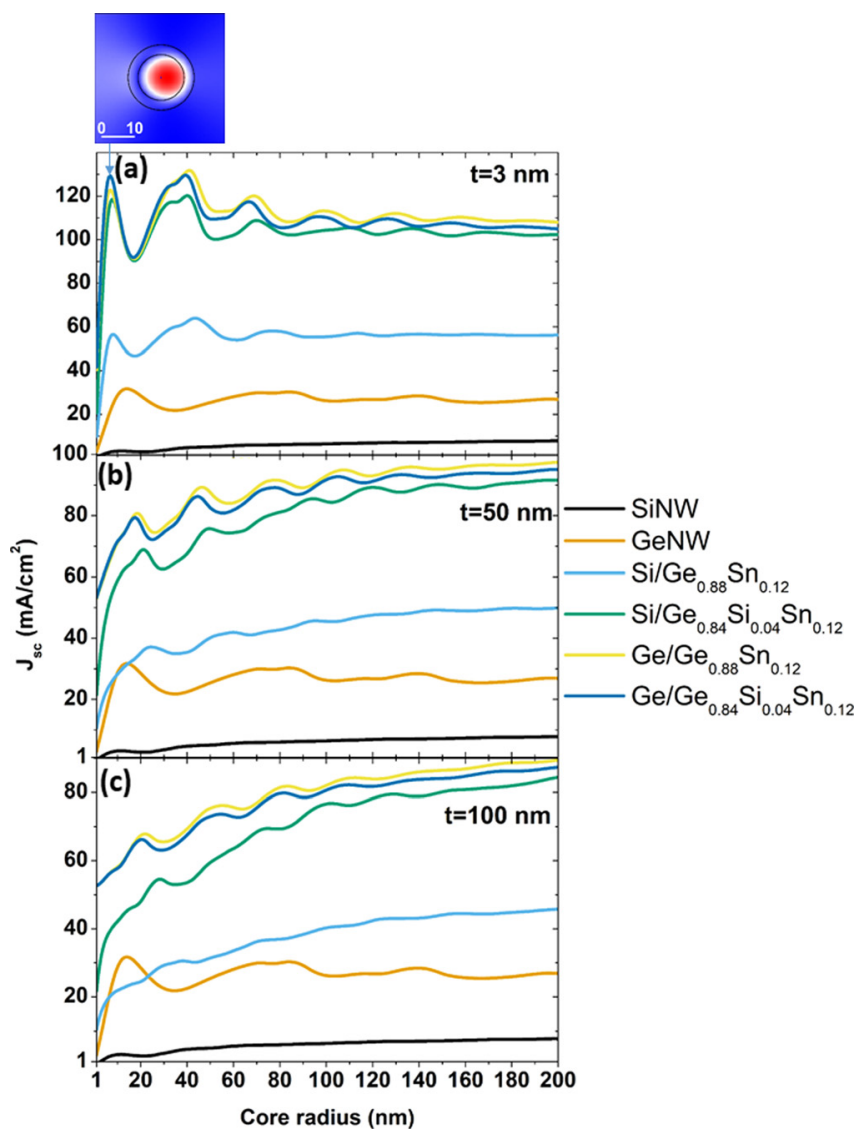

FIG. 7. Integrated solar absorption $\mathrm{J}_{\mathrm{sc}}\left(\mathrm{mA} / \mathrm{cm}^{2}\right)$ as a function of the core radius of the CSNWs consisting of absorbing group IV binary and ternary alloy semiconductor materials. We fix the shell thickness to (a) $3 \mathrm{~nm}$, (b) $50 \mathrm{~nm}$, and (c) $100 \mathrm{~nm}$ and plot the solar absorption as a function of the core radius for $\mathrm{Si} / \mathrm{Ge}_{0.88} \mathrm{Sn}_{0.12}, \quad \mathrm{Si} / \mathrm{Ge}_{0.84} \mathrm{Si}_{0.04} \mathrm{Sn}_{0.12}, \mathrm{Ge} / \mathrm{Ge}_{0.88} \mathrm{Sn}_{0.12}, \mathrm{Ge} /$ $\mathrm{Ge}_{0.84} \mathrm{Si}_{0.04} \mathrm{Sn}_{0.12}, \mathrm{GeNW}$, and $\mathrm{SiNW}$ structures. The solar absorption of the GeNW and the SiNW is presented for comparison sake, with a core radius equal to $R_{c}+t$ for a fair comparison, to easily visualize the enhancement of light absorption in these structures. We also show the near electric field profile at the highest achievable short-current at a shell thickness of $3 \mathrm{~nm}$ and a core radius of $7 \mathrm{~nm}$. We can infer from the profile distribution that the leaky fundamental mode is responsible for such a high short-current. 


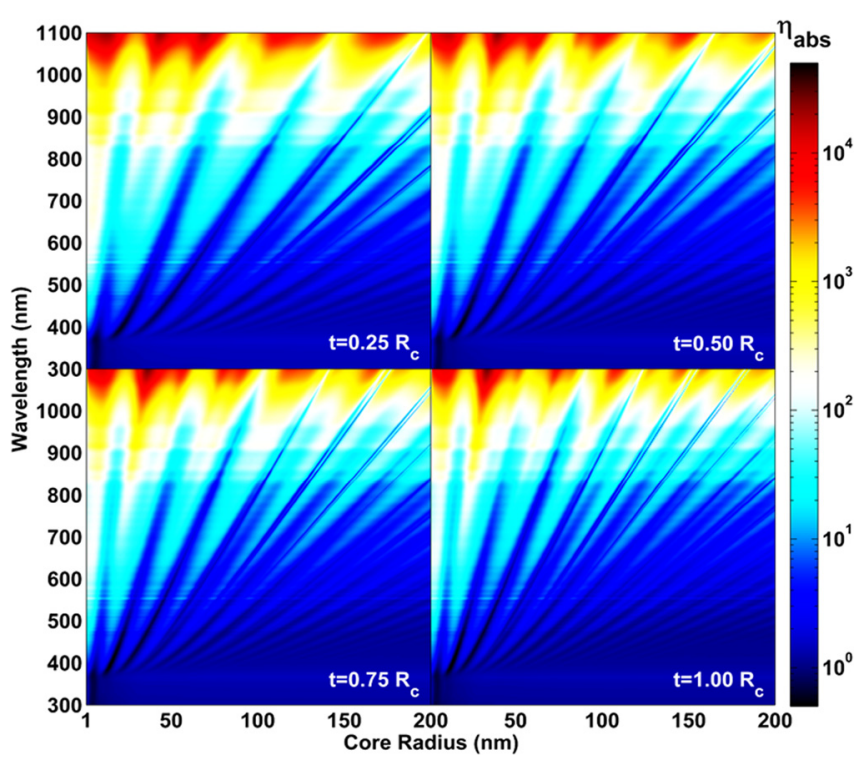

FIG. 8. Extreme light absorption enhancement map as a function of the core radius and the incident light wavelength for the $\mathrm{Si} / \mathrm{Ge}_{0.88} \mathrm{Sn}_{0.12}$ core-shell nanowire for different shell thicknesses $t=[0.25,0.5,0.75$, and 1$] \times R_{c}$.

by large core diameters. In the enhancement maps (Fig. 8 for $\mathrm{Si} / \mathrm{Ge}_{0.88} \mathrm{Sn}_{0.12}$, Fig. S4 in the supplementary material for $\mathrm{Si} /$ $\mathrm{Ge}_{0.84} \mathrm{Si}_{0.04} \mathrm{Sn}_{0.12}$, and Fig. S5 in the supplementary material for the $\mathrm{Ge} / \mathrm{Ge}_{0.88} \mathrm{Sn}_{0.12}$ ), a strong absorption enhancement that follows very specific directions is observed. In fact, when the incident wavelength matches one of the leaky modes supported by the NW, ${ }^{50,51}$ optical responses, including light scattering and absorption, were found to be substantially enhanced as compared to a simple SiNW. We observe a gradual increase in the enhancement of light absorption for the $\mathrm{Si} / \mathrm{GeSn}$ system compared to a SiNW where between 800 and $1000 \mathrm{~nm}, \eta_{a b s} \sim 10^{3}$. Next, between 1000 and $1100 \mathrm{~nm}$, $\eta_{\text {abs }}$ reaches its maximum $\sim 10^{4}$. For instance, at $r_{c}=33 \mathrm{~nm}$, $\lambda=1086 \mathrm{~nm}$, and $t=R_{c}, \eta_{a b s} \cong 3 \times 10^{4}$ for the $\mathrm{Si} / \mathrm{GeSn}$ CSNW. Additionally, when increasing the thickness of the shell, the leakier resonance modes are excited, which is reflected by the increase in the number of whiskers in the map: at $t=R_{c} / 4$, only five broad whiskers are observed, whereas at $t=R_{c}$, eight are found for $\mathrm{Si} / \mathrm{Ge}_{0.88} \mathrm{Sn}_{0.12}$ at the same core radius. Interestingly, the $\mathrm{Ge} / \mathrm{Ge}_{0.88} \mathrm{Sn}_{0.12} \mathrm{CSNW}$ enhancement map (see Fig. S5 in the supplementary material) displays a different result. Indeed, unlike the Si-based CSNW, the enhancement in the Ge-based CSNW is relatively small $\left(\sim 12\right.$ vs. $\left.\sim 10^{4}\right)$. Besides, above $700 \mathrm{~nm}$, the enhancement along the LMR is clear, and it reaches its maximum in the NIR region for $860 \leq \lambda \leq 1100 \mathrm{~nm}$ and $R_{c}$ $=42,37,32$, and $30 \mathrm{~nm}$ for each shell thickness $t$. Specifically, at $980 \leq \lambda \leq 1100 \mathrm{~nm}, \quad R_{c}=30 \mathrm{~nm}$, and $t=R_{c}$, we obtain an absorption enhancement factor $\eta_{a b s}$ between 9 and 12. This is in accordance with the shortcurrent enhancement map where at the same core radius and shell thickness, $\eta_{J_{s c}}$ is equal to 3.5 which is equivalent to a high short-current of $95 \mathrm{~mA} / \mathrm{cm}^{2}$.

The extreme enhancement of light absorption in $\mathrm{Si} /$ $\mathrm{GeSn}$ and $\mathrm{Si} / \mathrm{GeSiSn}$ structures presents an interesting opportunity to achieve optimal wavelength selectivity in the desired NIR region through an optimal choice of the core radius and shell thickness of the CSNW. We therefore need to optimize the physical dimensions $\left(R_{c}, t\right)$ of the CSNW in order to guarantee both photocurrent and absorption efficiency enhancement. Thus, for $\mathrm{Si} / \mathrm{Ge}_{0.88} \mathrm{Sn}_{0.12}$, we propose using core radii $R_{c}=17,41,70,113,132$, and $172 \mathrm{~nm}$ for a shell thickness $t=R_{c} / 4$, at which $Q_{a b s}$ is enhanced. In addition, when $R_{c}=6.3,17$, and $38 \mathrm{~nm}$, the short-circuit current is enhanced as shown in the red solid curve of Fig. 6(b) where the red arrows indicate the corresponding core radii. Thus, a core-radius of $17 \mathrm{~nm}$ would guarantee a simultaneous short-current and an absorption efficiency enhancement. Besides, for $t=R_{c}$, we find that the optimal core radii are $10,32,73,108$, and $149 \mathrm{~nm}$. On the other hand, for $\mathrm{Si} /$ $\mathrm{Ge}_{0.84} \mathrm{Si}_{0.04} \mathrm{Sn}_{0.12}$ and at $t=R_{c}$, we find the optimal radii to be $9,31,50,72,106,118$, and $147 \mathrm{~nm}$.

The investigations described above provide the basis to design high performance NW-based optoelectronic and photonic devices. In the following, we address the influence of an additional layer around the CSNW structure and elucidate the collective properties of an array of CSNWs. A single configuration will be considered: a non-absorbing dielectric layer $\left(\mathrm{Si}_{3} \mathrm{~N}_{4}\right)$ around an $\mathrm{Si} / \mathrm{Ge}_{0.88} \mathrm{Sn}_{0.12} \mathrm{CSNW}(\mathrm{Si} /$ $\mathrm{Ge}_{0.88} \mathrm{Sn}_{0.12} / \mathrm{Si}_{3} \mathrm{~N}_{4}$ ). (The optical properties of $\mathrm{Si}_{3} \mathrm{~N}_{4}$ are taken from Ref. 52.) The choice of silicon nitride $\left(\mathrm{Si}_{3} \mathrm{~N}_{4}\right)$ as a coating material emanates from two characteristics: first, the surface passivation effect ${ }^{53,54}$ and second the antireflective properties reducing light reflection considerably. Taking into consideration these aspects, we modeled light absorption and conversion in a $\mathrm{Si} / \mathrm{Ge}_{0.88} \mathrm{Sn}_{0.12} / \mathrm{Si}_{3} \mathrm{~N}_{4} \mathrm{NW}$. Because optical resonances serve to enhance the light-matter interaction of the NW cavity, we expect the dielectric-shell optical antenna effect to increase not only light scattering but also light absorption in photovoltaic (PV) devices. ${ }^{50}$ Fig. S1(c) in the supplementary material shows the geometrical configuration and the necessary parameters for the aforementioned system. Figure 9 displays the calculated short-current enhancement $\left(\eta_{J_{s c}}\right)$ at a fixed inner shell $(t)$ of the $\mathrm{Ge}_{0.88} \mathrm{Sn}_{0.12}$ layer equal to the core radius $\left(t=R_{c}\right)$, and we varied the dielectric capping layer thickness $D$ from 1 to $200 \mathrm{~nm}$. In the top and left panels in Fig. 9(a), we show the relative change in percent of the maximum short-current enhancement, i.e., a positive value means an enhancement or an increase in $J_{s c}$, whereas a negative value entails a deterioration or decay in $J_{s c}$ relative to a CSNW system without the dielectric layer. Additionally, the antireflection role of the dielectric shell can be further confirmed by examining the absorption spectra. We can see that the dielectric shell of the $\mathrm{Si} / \mathrm{Ge}_{0.88} \mathrm{Sn}_{0.12} / \mathrm{Si}_{3} \mathrm{~N}_{4}$ NW gives rise to a broad absorption peak, clearly shown in Figs. 9(b) and 9(c) for two distinct core radii (13.6 and $78.2 \mathrm{~nm}$ ). So, a core radius $R_{c}$ equal to $78.2 \mathrm{~nm}$ [green arrow in the top panel in Fig. 9(a)], an inner-shell thickness $t$ equal to the core radius, and a thickness of the dielectric capping layer $D$ equal to $43 \mathrm{~nm}$ [the blue arrow in the left panel of Fig. 9(a)] provide a $25 \%$ increase in the short-circuit current density and a high absorption efficiency. The enhancement at a smaller core radius $\left[R_{c}<20 \mathrm{~nm}\right.$; more specifically at $R_{c}=13.6 \mathrm{~nm}$, shown as an orange arrow in the top panel of Fig. 9(a) where an $\sim 40 \%$ increase in $J_{s c}$ is achieved] and at a 
capping layer thickness of $D=25 \mathrm{~nm}$ occurs where the LMR whiskers are present. This enhancement is explained by an increase in scattering. In fact, in the case of a subwavelength $\mathrm{NW}$, the increase in scattering is indicative of an enhanced optical antenna effect, which increases both scattering and absorption in the NW. This can be observed in Fig. 10(a).

Likewise, tuning the spectral range of the absorption throughout the dielectric layer thickness can be accomplished for a given core radius of $13.6 \mathrm{~nm}$ : in fact, when $D$ $=33 \mathrm{~nm}$, the structure will absorb in the visible spectrum, but when $D=3 \mathrm{~nm}$, the NIR spectrum will be active, with a $40 \%$ short-current enhancement compared to the $\mathrm{Si} /$ $\mathrm{Ge}_{0.88} \mathrm{Sn}_{0.12} \mathrm{CSNW}$ structure. Furthermore, when the core radius is increased to $78 \mathrm{~nm}$, the optimal $\mathrm{Si}_{3} \mathrm{Ni}_{4}$ capping layer thickness $D$ is found to be $45 \mathrm{~nm}$ from Fig. 9(c) with a corresponding short-current enhancement of $25 \%$.

Next, the effect of the additional dielectric layer can be better understood in Fig. 10(a) displaying TM-like mode absorption efficiency $\left(Q_{a b s}^{T M}\right)$ for three sets of NW structures: $\mathrm{Si}, \mathrm{Si} / \mathrm{Ge}_{0.88} \mathrm{Sn}_{0.12}$, and $\mathrm{Si} / \mathrm{Ge}_{0.88} \mathrm{Sn}_{0.12} / \mathrm{Si}_{3} \mathrm{~N}_{4}$ at $R_{c}=13.6$ and $75 \mathrm{~nm}$, and $D=33$ and $45 \mathrm{~nm}$, respectively, for each core radius. Figure 10(b) represents the resonant profiles of the total TM-polarized squared Poynting vector $|\mathbf{S}|_{T M}^{2}$ inside the nanostructure and displays a leaky-mode resonance behavior [see Fig. 10(b), maps 5 and 10], which is associated with the selective scattering of light in a specific wavelength depending on the structure size. The NWs are investigated at wavelengths corresponding to the peaks labeled 1 to 10 in Fig. 10(a). When coating the $\mathrm{Si} / \mathrm{Ge}_{0.88} \mathrm{Sn}_{0.12} \mathrm{CSNW}$ with the $\mathrm{Si}_{3} \mathrm{~N}_{4}$ layer, an increase in the absorption efficiency is apparent regardless of the core radius.

Note that adding a GeSn shell and increasing the core radius will induce a redshift in the LMR spectral position where higher order modes were observed to appear. Furthermore, the number of excited LMR diminishes due to the presence of the dielectric capping layer. The opportunity to control the spatial distribution of the energy flux density in the three aforementioned structures, by introducing a shell layer, provides wavelength tunability of the absorption efficiency which is clearer in the absorption maps presented in Fig. 10(b). Besides, we demonstrate that a simple dielectric shell can double light absorption and dramatically increase light scattering in $\mathrm{Si}$ core NWs by enhancing the optical antenna effect of the wires. This effect has been proven for different dielectric layers $\left(\mathrm{SiO}_{2}\right) .{ }^{55}$

\section{CONCLUSION}

In summary, we have demonstrated LMR-induced field enhancements inside $\mathrm{Ge}_{1-\mathrm{x}-\mathrm{y}} \mathrm{Si}_{\mathrm{x}} \mathrm{Sn}_{\mathrm{y}}$ alloy heterostructures and core-shell nanowires. Our theoretical calculations
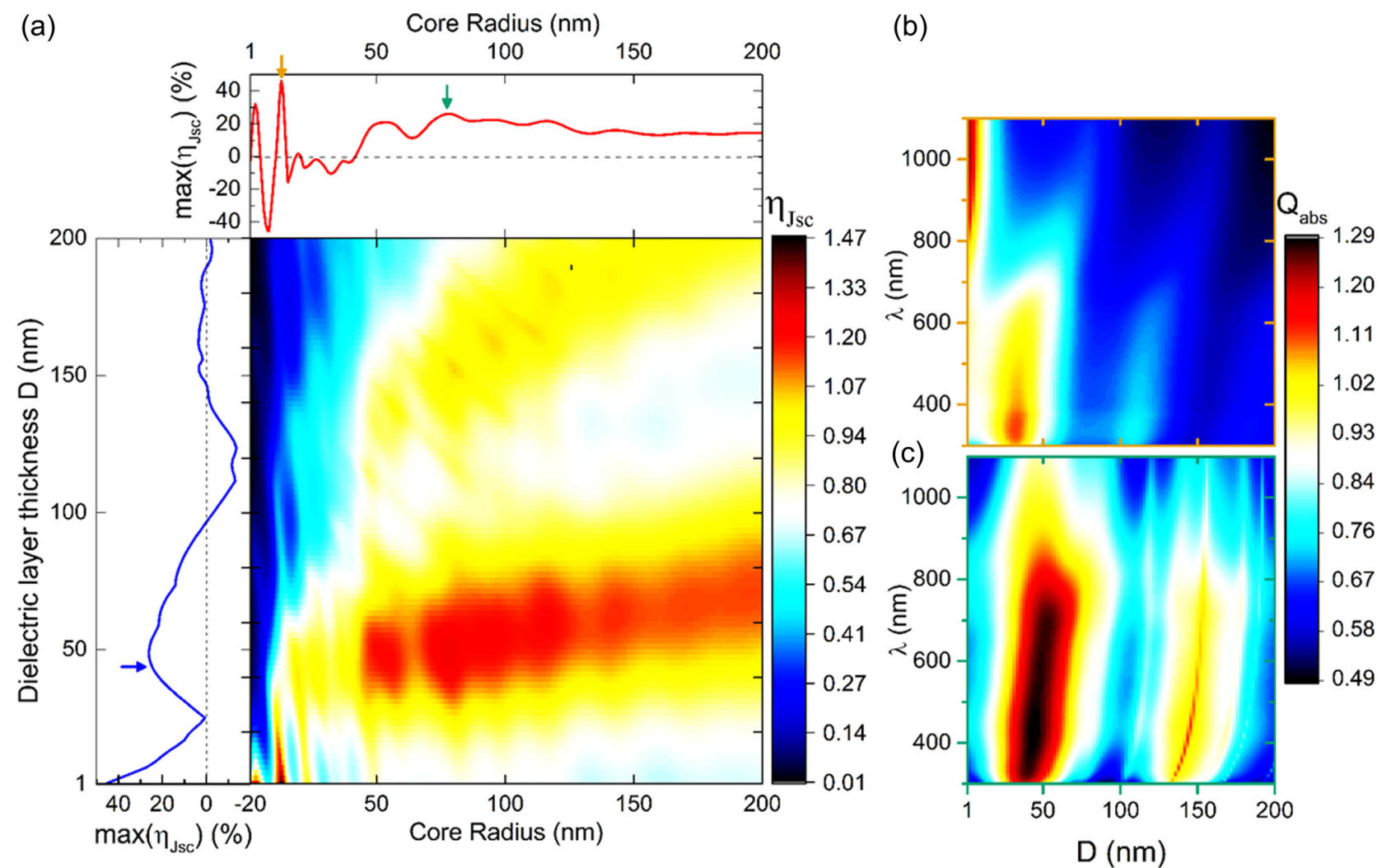

FIG. 9. (a) The short-current enhancement map of the $\left(\mathrm{Si} / \mathrm{Ge}_{0.88} \mathrm{Sn}_{0.12} / \mathrm{Si}_{3} \mathrm{~N}_{4}\right)$ system where we fixed the inner-shell thickness to be equal to the core radius $\left(t_{i . s .}=R_{c}\right)$, and we varied the dielectric capping layer thickness $D$ from 1 to $200 \mathrm{~nm}$. The top panel shows the relative maximum change in the short-current enhancement $\left[\max \left(\eta_{J s c}\right)\right.$ in \%] vs. the core radius, whereas the left panel represents the relative change in max $\left(\eta_{J s c}\right) v s$. $D$. The relative change is evaluated using the following equation: $\left(\eta_{J s c}-1\right) \times 100$. The short-current enhancement was evaluated as the ratio of the short-current of the core-multishell nanowire to the short-current of the base CSNW ( $\mathrm{Si} / \mathrm{GeSn})\left(\eta_{J_{s c}}=J_{s c}^{\mathrm{Si} / \mathrm{GeSn} / \mathrm{SiN}} / J_{s c}^{S i / G e S n}\right)$. The orange and green arrows in the top panel represent the core radii $R_{c}$ equal to 13.6 and $78.2 \mathrm{~nm}$, respectively, where $J_{s c}$ is enhanced. Next, fixing $R_{c}$ to the previous radii, we present in panels (b) and (c) a $2 \mathrm{D}$ map of the absorption efficiency $Q_{a b s}$ as a function of the incident wavelength $\lambda$ and the dielectric thickness $D$. 
(a)

(b)

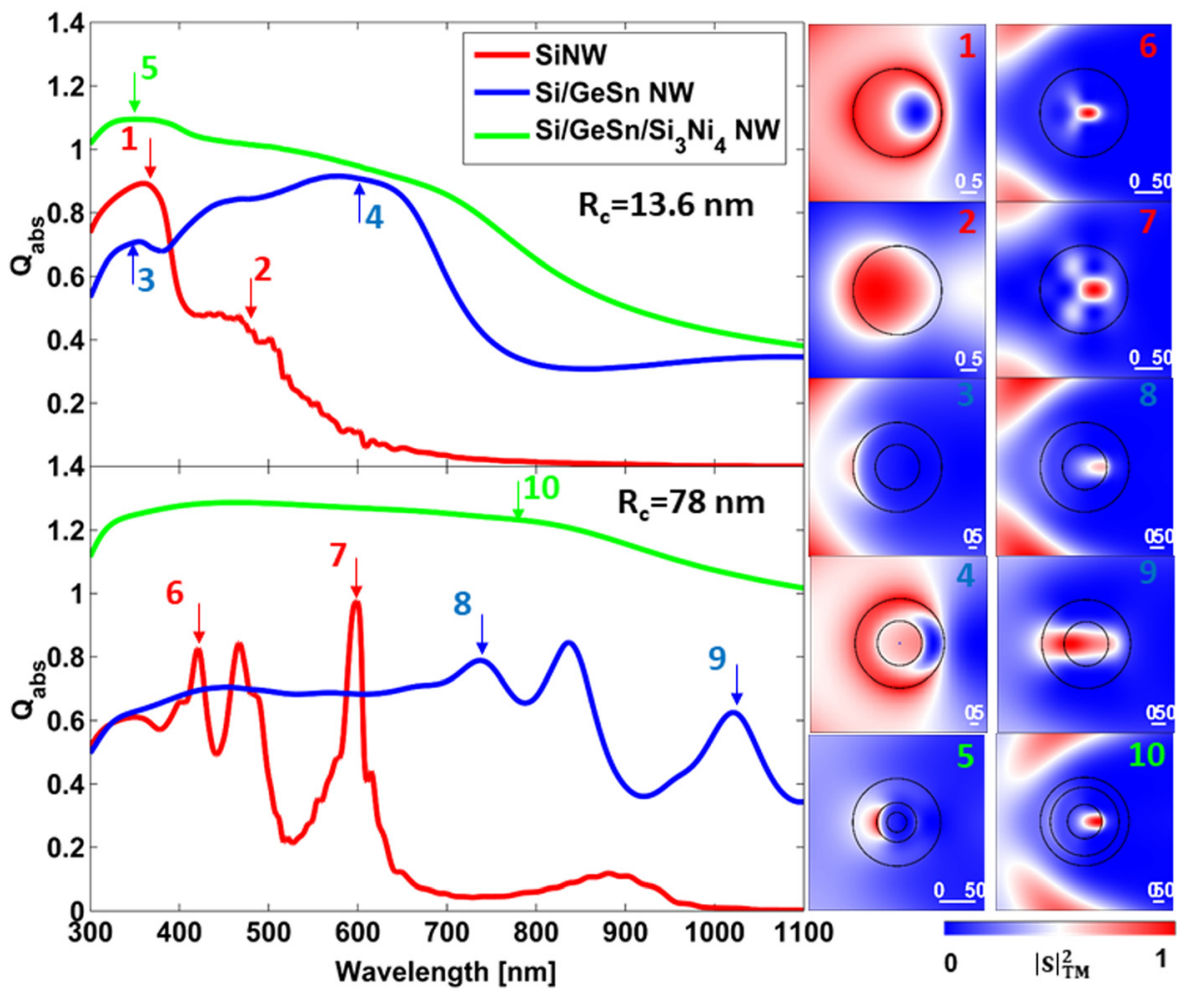

FIG. 10. (a) TM-like mode absorption efficiency $\left(Q_{a b s}^{T M}\right)$ of the Si NW structure (red curve), $\quad \mathrm{Si} / \mathrm{Ge}_{0.88} \mathrm{Sn}_{0.12}$ CSNW structure (blue curve), and $\mathrm{Si} /$ $\mathrm{Ge}_{0.88} \mathrm{Sn}_{0.12} / \mathrm{Si}_{3} \mathrm{~N}_{4}$ structure (green curve), surrounded by air, for 2 different core radii : $R_{c}=13.6$ and $78 \mathrm{~nm}$. We kept the GeSn shell thickness fixed to the core radius, and the dielectric capping layer $D$ is chosen to be 33 and $45 \mathrm{~nm}$, respectively, for each core radius. We also label the resonant peaks 1-10 for different structures. (b) Near field magnitude for the total TMpolarized Poynting vector $|\mathbf{S}|_{T M}^{2}$ by the three different structures evaluated with the analytical solution for a perpendicular incident illumination at the wavelengths corresponding to the peaks labeled $1-10$ in panel (a). We also present the corresponding scale bar for each structure.

demonstrated that a $\sim 14$-fold increase in photocurrent can be achieved in $\mathrm{Si} / \mathrm{Ge}_{1-\mathrm{x}-\mathrm{y}} \mathrm{Si}_{\mathrm{x}} \mathrm{Sn}_{\mathrm{y}}$ heterostructures as compared to bare Si. Furthermore, when we decrease the outer layer thickness relative to the core radius in the core-shell nanowires, we obtain an increase in the maximum short-circuit current enhancement factor. Conversely, a thinner Sncontaining top layer limits the enhancement of light absorption in the thin films. Moreover, the photocurrent increase in nanowires is found to be restricted to narrow regions (core radius $R_{c}<56 \mathrm{~nm}$ and shell thickness $t<40 \mathrm{~nm}$ ) where a significant enhancement relative to $\mathrm{Si}$ nanowires is achieved, reaching 11-22-fold for $\mathrm{Si} / \mathrm{Ge}_{0.88} \mathrm{Sn}_{0.12}$ and 25-47-fold for $\mathrm{Si} / \mathrm{Ge}_{0.84} \mathrm{Si}_{0.04} \mathrm{Sn}_{0.12}$ core-shell nanowires. Additionally, we showed an extreme enhancement of light absorption for $\mathrm{Si}$ / $\mathrm{GeSn}$, where the absorption efficiency in the near-infrared region is four orders of magnitude higher than that of SiNW. For $\mathrm{Ge} / \mathrm{Ge}_{1-\mathrm{y}-\mathrm{x}} \mathrm{Si}_{\mathrm{x}} \mathrm{Sn}_{\mathrm{y}}$ core-shell nanowires, the enhancement in light absorption is relatively limited as compared to $\mathrm{Si} /$ $\mathrm{Ge}_{1-\mathrm{y}-\mathrm{x}} \mathrm{Si}_{\mathrm{x}} \mathrm{Sn}_{\mathrm{y}}$ core-shell nanowires. The observed enhancement is due to a multiplication of contributions from LMRs in both core and shell semiconductors. These effects can be exploited through the control over the size and composition of the nanowire structure. Moreover, the calculations also suggest that the addition of a $\mathrm{Si}_{3} \mathrm{~N}_{4}$ ARC layer on $\mathrm{Si}$ / $\mathrm{Ge}_{1-\mathrm{y}-\mathrm{x}} \mathrm{Si}_{\mathrm{x}} \mathrm{Sn}_{\mathrm{y}}$ core-shell nanowires improves the absorption efficiency. ${ }^{57}$ In fact, by tuning the core radius and the dielectric layer thickness, it is possible to selectively control the spectral range (visible or NIR) where the structure becomes optically active. For instance, with a core radius larger than $75 \mathrm{~nm}$ and a dielectric layer thickness of $40 \mathrm{~nm}$, a $30 \%$ increase in the generated photocurrent relative to $\mathrm{Si} /$ $\mathrm{Ge}_{1-\mathrm{y}-\mathrm{x}} \mathrm{Si}_{\mathrm{x}} \mathrm{Sn}_{\mathrm{y}}$ core-shell nanowires can be achieved. The obtained results indicate that $\mathrm{Si}$-based nanowire structures are more advantageous in terms of absorption enhancement as compared to thin films for applications in solar cells and photodetectors.

\section{SUPPLEMENTARY MATERIAL}

See supplementary material for a detailed explanation of the ellipsometry measurements (S1), an extension of the Lorentz-Mie scattering theory to incorporate random illumination (S2), a benchmarking study of the Mie-Lorentz scattering calculation by comparing it to already published experimental data (S3), description of the full-vector finite-difference (FVFD) complex mode solver used to extract the resonance modes for CSNW (S4), and finally, light absorption enhancement maps in $\mathrm{Si} / \mathrm{Ge}_{0.88} \mathrm{Sn}_{0.12}$ and $\mathrm{Si} / \mathrm{Ge}_{0.84} \mathrm{Si}_{0.04} \mathrm{Sn}_{0.12}$ (S5).

\section{ACKNOWLEDGMENTS}

O.M. acknowledges the support from NSERC-Canada (Discovery Grants), Canada Research Chair, Fondation de l'École Polytechnique de Montréal, MRIF Québec, Calcul Québec, and Computer Canada. Computations were made on a supercomputer managed by Calcul Québec and Compute Canada. The operation of this supercomputer was funded by the Canada Foundation for Innovation (CFI), ministère de l'Économie, de la Science et de l'Innovation du Québec (MESI), and the Fonds de recherche du Québec-Nature et technologies (FRQ-NT). A.A. is grateful for technical help from Mr. Bart Oldeman and the Calcul Québec-McGill support team.

${ }^{1}$ M. L. Brongersma, Y. Cui, and S. Fan, Nat. Mater. 13, 451 (2014).

${ }^{2}$ P. E. Landreman and M. L. Brongersma, Nano Lett. 14, 429 (2014). 
${ }^{3}$ A. L. Falk, F. H. L. Koppens, C. L. Yu, K. Kang, N. de Leon Snapp, A. V. Akimov, M.-H. Jo, M. D. Lukin, and H. Park, Nat. Phys. 5, 475 (2009).

${ }^{4}$ N. Tanaka, Technology Roadmap: Solar Photovoltaic Energy (International Energy Agency, 2010).

${ }^{5}$ W. A. Nositschka, C. Beneking, O. Voigt, and H. Kurz, Sol. Energy Mater. Sol. Cells 76, 155 (2003).

${ }^{6}$ B. W. Schneider, N. N. Lal, S. Baker-Finch, and T. P. White, Opt. Express 22, A1422 (2014)

${ }^{7}$ W. Lu and C. M. Lieber, Nat. Mater. 6, 841 (2007).

${ }^{8}$ Z. Fan, D. Wang, P. C. Chang, W. Y. Tseng, and J. G. Lu, Appl. Phys. Lett. 85, 5923 (2004)

${ }^{9}$ L. J. Lauhon, M. S. Gudiksen, D. Wang, and C. M. Lieber, Nature 420, 57 (2002).

${ }^{10}$ H. Goto, K. Nosaki, K. Tomioka, S. Hara, K. Hiruma, J. Motohisa, and T. Fukui, Appl. Phys. Express 2, 035004 (2009).

${ }^{11}$ B. Tian, X. Zheng, T. J. Kempa, Y. Fang, N. Yu, G. Yu, J. Huang, and C. M. Lieber, Nature 449, 885 (2007).

${ }^{12}$ L. Cao, P. Fan, A. P. Vasudev, J. S. White, Z. Yu, W. Cai, J. A. Schuller, S. Fan, and M. L. Brongersma, Nano Lett. 10, 439 (2010).

${ }^{13}$ Y. Yu, V. E. Ferry, A. P. Alivisatos, and L. Cao, Nano Lett. 12, 3674 (2012).

${ }^{14}$ J. A. Schuller and M. L. Brongersma, Opt. Express 17, 24084 (2009).

${ }^{15}$ L. Tang, S. E. Kocabas, L. Salman, A. K. Okyay, D.-S. Ly-Gagnon, K. C. Saraswat, and D. A. B. Miller, Nat. Photonics 2, 226 (2008).

${ }^{16}$ D. Ahn, C.-Y. Hong, J. Liu, W. Giziewicz, M. Beals, L. C. Kimerling, J. Michel, J. Chen, and F. X. Kärtner, Opt. Express 15, 3916 (2007).

${ }^{17}$ S. O'Brien and J. B. Pendry, J. Phys. Condens. Matter 14, 4035 (2002).

${ }^{18} \mathrm{~J}$. A. Schuller, R. Zia, T. Taubner, and M. L. Brongersma, Phys. Rev. Lett. 99, 107401 (2007).

${ }^{19}$ O. L. Muskens, S. L. Diedenhofen, M. H. M. Van Weert, M. T. Borgström, EP. a M. Bakkers, and J. G. Rivas, Adv. Funct. Mater. 18, 1039 (2008).

${ }^{20}$ J. A. Schuller, T. Taubner, and M. L. Brongersma, Nat. Photonics 3, 658 (2009).

${ }^{21}$ J. Kouvetakis, J. Menendez, and A. V. G. Chizmeshya, Annu. Rev. Mater. Res. 36, 497 (2006)

${ }^{22}$ S. Wirths, D. Buca, and S. Mantl, Prog. Cryst. Growth Charact. Mater. 62, 1 (2016).

${ }^{23}$ A. Attiaoui and O. Moutanabbir, J. Appl. Phys. 116, 63712 (2014).

${ }^{24}$ R. A. Soref and C. H. Perry, J. Appl. Phys. 69, 539 (1991).

${ }^{25}$ K. Zelazna, M. Welna, J. Misiewicz, J. Dekoster, and R. Kudrawiec, J. Phys. D. Appl. Phys. 49, 235301 (2016).

${ }^{26}$ S. A. Ghetmiri, W. Du, J. Margetis, A. Mosleh, L. Cousar, B. R. Conley, L. Domulevicz, A. Nazzal, G. Sun, R. A. Soref, J. Tolle, B. Li, H. A. Naseem, and S. Q. Yu, Appl. Phys. Lett. 105, 151109 (2014).

${ }^{27}$ J. M. Hartmann, A. Abbadie, A. M. Papon, P. Holliger, G. Rolland, T. Billon, J. M. Fédéli, M. Rouvière, L. Vivien, and S. Laval, J. Appl. Phys. 95, 5905 (2004)

${ }^{28}$ J. M. Hartmann, A. Abbadie, N. Cherkashin, H. Grampeix, and L. Clavelier, Semicond. Sci. Technol. 24, 55002 (2009).

${ }^{29}$ V. A. Shah, A. Dobbie, M. Myronov, and D. R. Leadley, Solid State Electron. 62, 189 (2011).

${ }^{30}$ J. A. Woollam, "Ellipsometry, variable angle spectroscopic," in Wiley Encyclopedia of Electrical and Electronics Engineering (Wiley, New York, NY, 2000).
${ }^{31}$ R. W. Olesinski and G. J. Abbaschian, Bull. Alloy Phase Diagrams 5, 265 (1984).

${ }^{32}$ J.-H. Fournier-Lupien, S. Mukherjee, S. Wirths, E. Pippel, N. Hayazawa, G. Mussler, J. M. Hartmann, P. Desjardins, D. Buca, and O. Moutanabbir, Appl. Phys. Lett. 103, 263103 (2013).

${ }^{33}$ C. F. Bohren and D. R. Huffman, Absorption and Scattering of Light by Small Particles (John Wiley \& Sons, Ltd, New York, NY, 1998).

${ }^{34}$ G. Brönstrup, N. Jahr, C. Leiterer, A. Csáki, W. Fritzsche, and S. Christiansen, ACS Nano 4, 7113 (2010).

${ }^{35}$ H. Kallel, A. Chehaidar, A. Arbouet, and V. Paillard, J. Appl. Phys. 114, 224312 (2013).

${ }^{36}$ W. F. Liu, J. I. Oh, and W. Z. Shen, IEEE Electron Device Lett. 32, 45 (2011).

${ }^{37}$ W. Q. Xie, W. F. Liu, J. I. Oh, and W. Z. Shen, Appl. Phys. Lett. 99, 33107 (2011).

${ }^{38}$ Standard Tables for Reference Solar Spectral Irradiances, Standard G173-03e (The American Society for Testing and Materials, 2006).

${ }^{39}$ S. Wirths, R. Geiger, N. V. Den Driesch, G. Mussler, T. Stoica, S. Mantl, Z. Ikonic, M. Luysberg, S. Chiussi, J. M. Hartmann, H. Sigg, J. Faist, D. Buca, and D. Grützmacher, Nat. Photonics 9, 88 (2015).

${ }^{40}$ L. Cao, J. S. White, J.-S. Park, J. a Schuller, B. M. Clemens, and M. L. Brongersma, Nat. Mater. 8, 643 (2009).

${ }^{41}$ J. Il Oh, W. Liu, W. Xie, and W. Shen, in Silicon-Based Nanomaterials, edited by H. Li, J. Wu, and Z. M. Wang (Springer, New York, NY, 2013).

${ }^{42}$ A. W. Snyder, Optical Waveguide Theory (Springer, Berlin/Heidelberg, 1983).

${ }^{43}$ L. A. A. Pettersson, L. S. Roman, and O. Inganäs, J. Appl. Phys. 86, 487 (1999)

${ }^{44}$ Y. C. Lu, L. Yang, W. P. Huang, and S. S. Jian, J. Lightwave Technol. 26, 1868 (2008).

${ }^{45}$ G. Grzela, R. Paniagua-Domínguez, T. Barten, Y. Fontana, J. A. SánchezGil, and J. G. Rivas, Nano Lett. 12, 5481-5486 (2012).

${ }^{46}$ M.-K. Seo, J.-K. Yang, K.-Y. Jeong, H.-G. Park, F. Qian, H.-S. Ee, Y.-S. No, and Y.-H. Leet, Nano Lett. 8, 4534 (2008).

${ }^{47}$ T. Khudiyev, E. Huseyinoglu, and M. Bayindir, Sci. Rep. 4, 4607 (2014).

${ }^{48}$ U. Fano, Phys. Rev. 124, 1866 (1961).

${ }^{49}$ W. Shockley and H. J. Queisser, J. Appl. Phys. 32, 510 (1961).

${ }^{50}$ L. Cao, P. Fan, E. S. Barnard, A. M. Brown, and M. L. Brongersma, Nano Lett. 10, 2649 (2010).

${ }^{51}$ L. Cao, J.-S. Park, P. Fan, B. Clemens, and M. L. Brongersma, Nano Lett. 10, 1229 (2010).

${ }^{52}$ J. Kischkat, S. Peters, B. Gruska, M. Semtsiv, M. Chashnikova, M. Klinkmüller, O. Fedosenko, S. Machulik, A. Aleksandrova, G. Monastyrskyi, Y. Flores, and W. Ted Masselink, Appl. Opt. 51, 6789 (2012).

${ }^{53}$ M. J. Kerr and A. Cuevas, Semicond. Sci. Technol. 17, 166 (2002).

${ }^{54}$ H. MäcKel and R. Lüdemann, J. Appl. Phys. 92, 2602 (2002).

${ }^{55}$ S.-K. Kim, X. Zhang, D. J. Hill, K.-D. Song, J.-S. Park, H.-G. Park, and J. F. Cahoon, Nano Lett. 15, 753 (2015).

${ }^{56}$ E. D. Palik, Handbook of Optical Constants of Solids (Academic Press, London, UK, 1998).

${ }^{57}$ S. Assali, A. Dijkstra, A. Li, S. Koelling, M. A. Verheijen, L. Gagliano, N. von den Driesch, D. Buca, P. M. Koenraad, J. E. M. Haverkort, and E. P. A. M. Bakkers, Nano Lett. 17, 1538 (2017). 